\title{
Cold Wire Gas Metal Arc Welding: Droplet Transfer and Geometry
}

\section{Bead-on-plate welds were performed to investigate the metal transfer dynamics and its influence on dilution and melting efficiency for three natural transfer modes}

\author{
R. A. RIBEIRO, E. B. F. DOS SANTOS, P. D. C. ASSUNÇÃO, E. M. BRAGA, AND A. P. GERLICH
}

\begin{abstract}
The metal transfer dynamics induced by cold wire additions were examined during the three natural transfer modes in welding: short circuit (low arc power), globular (intermediate arc power), and spray (high arc power), and their implications on weld bead geometry, dilution, and melting efficiency were evaluated during cold wire gas metal arc welding (CW-GMAW). Bead-on-plate welds were conducted on $3 / 8$-in. (9.52-mm) -thick AISI 1020 steel plates. Data acquisition of the electrical signals were synchronized with highspeed imaging to study the arc dynamics. Standard metallographic procedures were used to study dilution, allowing the melting efficiency to be estimated. The results provide evidence that increasing cold wire feeding rates will favor arc attachment to the cold wire rather than to the weld pool for all natural transfer modes. This influences dilution of the welds along with the melting efficiency. The findings are used to identify conditions where CW-GMAW offers higher melting efficiency than the standard GMAW process.
\end{abstract}

\section{KEYWORDS}

- Gas Metal Arc Welding (GMAW) - Arc Physics

- Heat Transfer • Carbon and Low-Alloy Steels

\section{Introduction}

Productivity and reliability are vital to advanced manufacturing technology, and this includes welding processes, which are prominent in metal fabrication. To achieve these goals in welding, processes with increasingly advanced and hybrid technologies are being more widely used. Welding melting rate (in units of $\mathrm{kg} / \mathrm{h}$ ) is considered here as an indication of overall productivity in welding, which also depends on other factors such as welding speed, arc time, and welding defect rate according to general manufacturing definitions (Ref. 1). Moreover, according to Suban and Tušek (Ref. 2 ), melting rate is the most prominent factor to assess welding productivity. For this reason, it is taken here as a reference for assessing welding productivity.
To decouple productivity/melting rate from the heat input, several techniques can be employed. These include double electrode gas metal arc welding (DE-GMAW), cold wire submerged arc welding (CW-SAW), and cross arc GMAW, which are outlined as follows.

A recently developed technique is DE-GMAW, which uses a bypass electrode to limit the amount of current passing through the workpiece. The effect of bypass current on arc stability and metal transfer was studied by Li and Zhang (Ref. 3). Using two GMAW power sources, the bypass current was held constant, which improved metal transfer stability in spray transfer, and consequently nearly doubled the productivity over standard GMAW.

The consequences of these process modifications to increase productivity can also be noted in the reduced heating of the heat-affected zone (HAZ), which leads to improved properties. For example, Mohammadijoo et al. examined CW-SAW and showed the deposition rate was increased by $6 \%$ due to cold wire (Ref. 4). In addition, the prior austenite grain size (PAGS) in the coarse-grained heat-affected zone (CGHAZ) was reduced due to the decrease in the heat input to the workpiece. Meanwhile, the HAZ fracture toughness (Ref. 5) was increased due to the reduction of the fraction of martensite-austenite.

A further development in welding processes is the cross arc GMAW, or CA-GMAW, as proposed in a preliminary report by Chen et al. (Ref. 6). Generally, a cross arc is established between a gas tungsten arc welding (GTAW) electrode and two carbon electrodes aiming to decouple deposition and heat input. The interwire current is related to the ionization degree of the arc, and the authors reported that this process is stable for different levels of GTAW currents. Moreover, the stability increases with GTAW current, which allows deposition to be controlled separately from heat input. Another approach to increasing the productivity of a welding process is by enhancing the melting efficiency, which represents the magnitude of the arc net power that is devoted to melting the base and filler metals. This improvement in melting efficiency is achieved when a larger fraction of the arc energy is used to create and sustain the melting pool. Based on the work of DuPont and Marder (Ref. 7), it is thought that the maximum value of melting efficiency for 

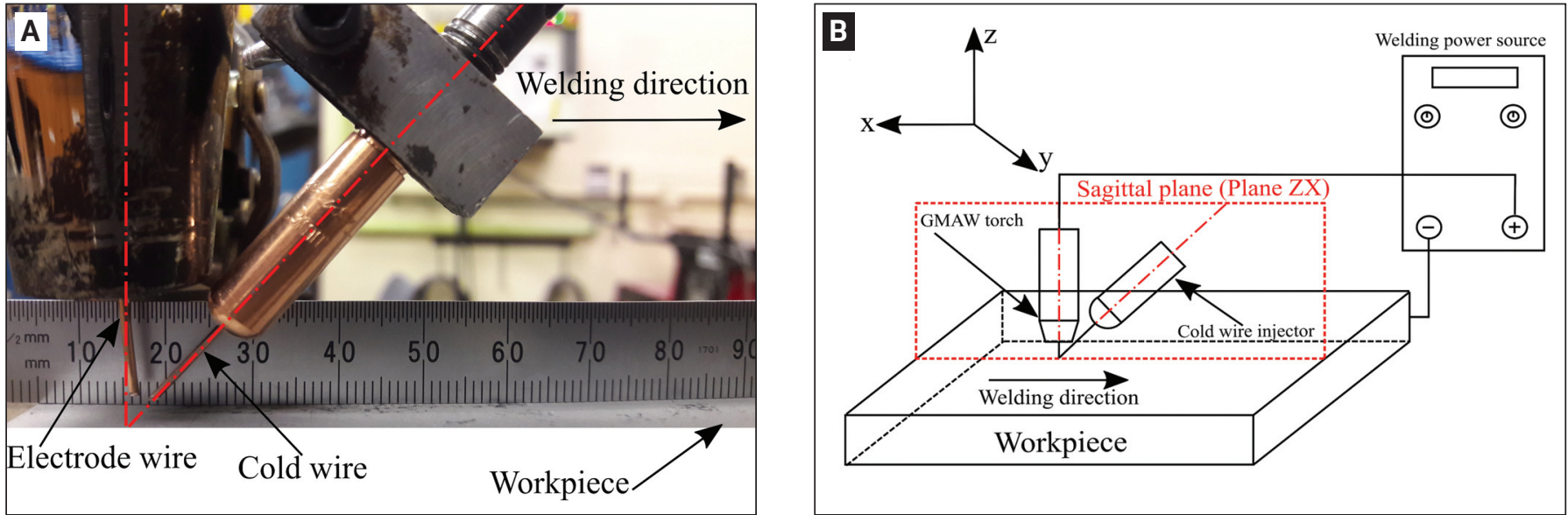

Fig. 1-General welding setup. A - Photograph showing the components of the setup; B - schematics showing the GMAW torch and cold wire injector are coplanar (sagittal plane).

an arc-shielded welding process is around 0.5 or $50 \%$ due to the intrinsic heat losses of the weld pool. Recently, Hackenhaar et al. examined the melting efficiency of GMAW using a Box-Behnken designed experiment, and it was found that melting efficiency depends on the geometry of the welded part, which is consistent with differences in energy distribution and losses. Comparing the values of melting efficiency for joints and beads on plates, the reported values obeyed the general limit of 0.5 (Ref. 8). Moreover, joints presented lower melting efficiency, which is consistent with 3D heat flow regime.

To provide an alternative to such costly and specialized equipment in these welding processes, CW-GMAW was developed. This was originally proposed to provide higher deposition in shipbuilding applications (Ref. 9), where decreasing the heat-induced distortion can be achieved by simply using an additional wire feeder to feed cold wire to the weld pool. Subsequently, Ribeiro et al. (Ref. 10) showed that cold wire introduction leads to a slight increase in current without consequent increase in penetration. Moreover, Assunção et al. (Ref. 11) successfully demonstrated the use of CW-GMAW can facilitate 5 -mm-wide narrow gap welding. A key point was shown in that CW-GMAW prevents detrimental sidewall erosion, and decreases the HAZ width in comparison to conventional GMAW. Further research on CW-GMAW by Costa et al. (Ref. 12) using an acoustic birefringence technique provided evidence that the use of cold wire reduces residual stress, and consequently there is evidence that CW-GMAW manufactured joints offer superior fatigue life, using standard fatigue tests and metallographic techniques, when compared to GMAW joints as proposed by Marques et al. (Ref. 13).

To validate the CW-GMAW and foster new applications, the present work evaluated the modifications to metal

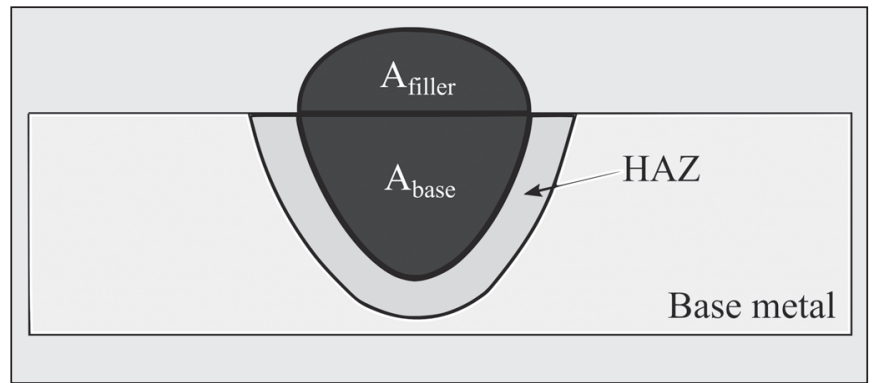

Fig. 2 - Schematic for dilution and melting efficiency.

transfer induced by the cold wire feeding (nonenergized) in CW-GMAW for the three natural transfer modes: short circuit, globular, and spray. The results have shown that with the increase of cold wire feed rates, the arc attaches progressively more to the cold wire, leading to changes in dilution and melting efficiency. Moreover, estimates of melting efficiency were calculated assuming an average value of arc efficiency. A main focus is the potential to decouple welding deposition and nominal heat input during CW-GMAW, which is a key feature of new welding processes.

\section{Experimental Methodology}

Bead-on-plate welds were performed on hot rolled AISI 1020 plates measuring $300 \mathrm{~mm}$ long, $150 \mathrm{~mm}$ wide, and $9.52 \mathrm{~mm}$ thick. AWS ER70S-6 (Ref. 14) was used as an energized electrode and the nonenergized cold wire with nominal diameters of $1.2 \mathrm{~mm}$ (0.045 in.) and $0.9 \mathrm{~mm}$ (0.035 in.), respectively. Table 1 presents the nominal compositions of the base metal and welding wires used.

Table 1- Nominal Chemical Composition of the Base Metal and Welding Wire

Nominal Chemical Composition (wt-\%)

Material

\begin{tabular}{lccccccc} 
& $\mathrm{C}$ & $\mathrm{Si}$ & $\mathrm{Mn}$ & $\mathrm{P}$ & $\mathrm{S}$ & $\mathrm{Cr}$ & $\mathrm{Fe}$ \\
AISI 1020 Plate & 0.18 & - & 0.30 & - & Max. 0.005 & - & Balance \\
ER 70S-6 Wire & 0.15 & 1.15 & 1.85 & 0.025 & 0.035 & 0.05 & Balance \\
\hline
\end{tabular}



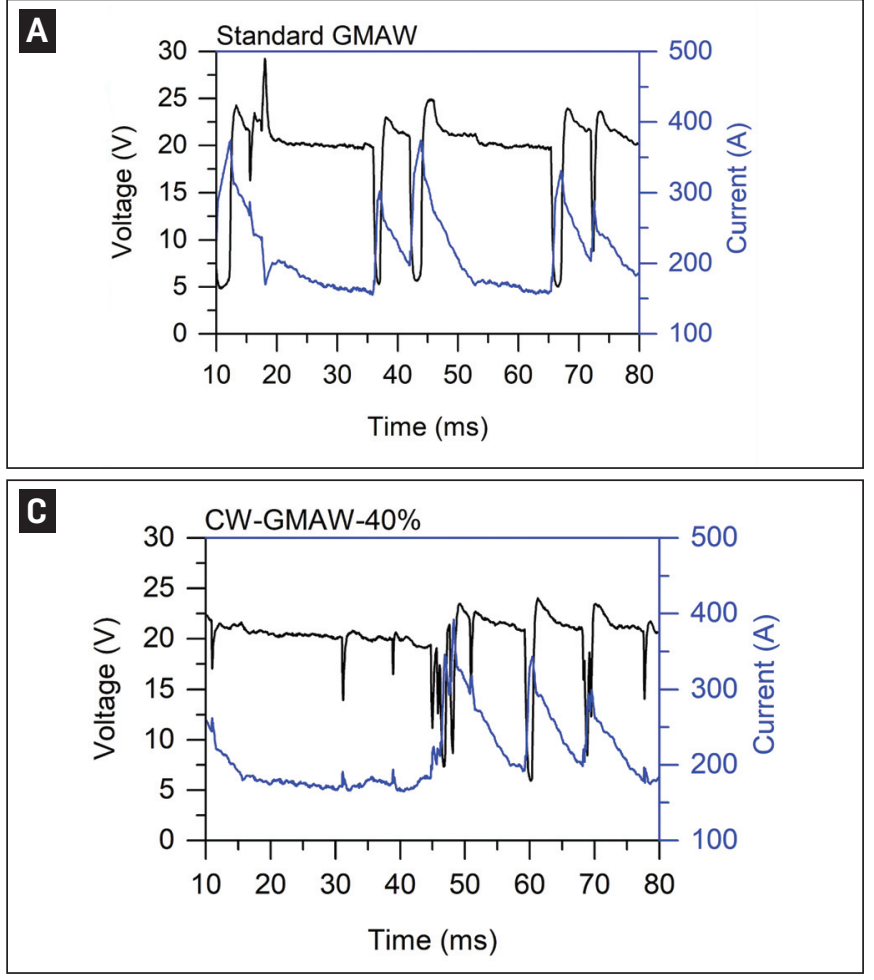

$\mathbf{E}$

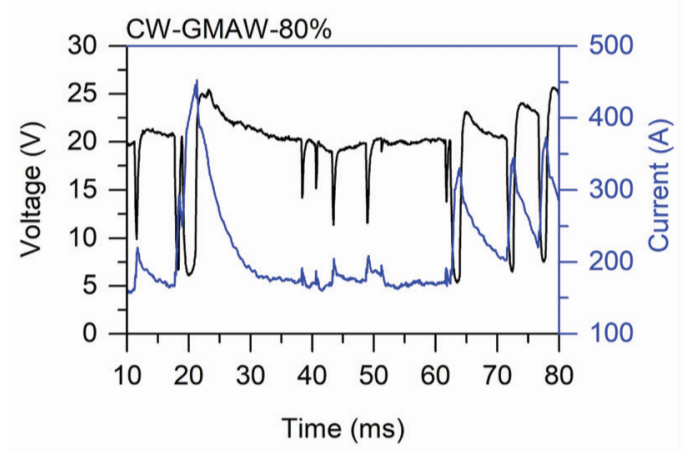

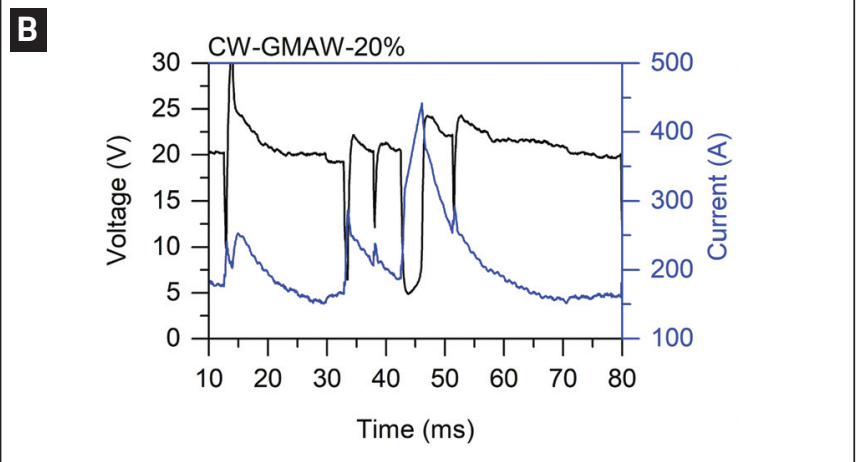
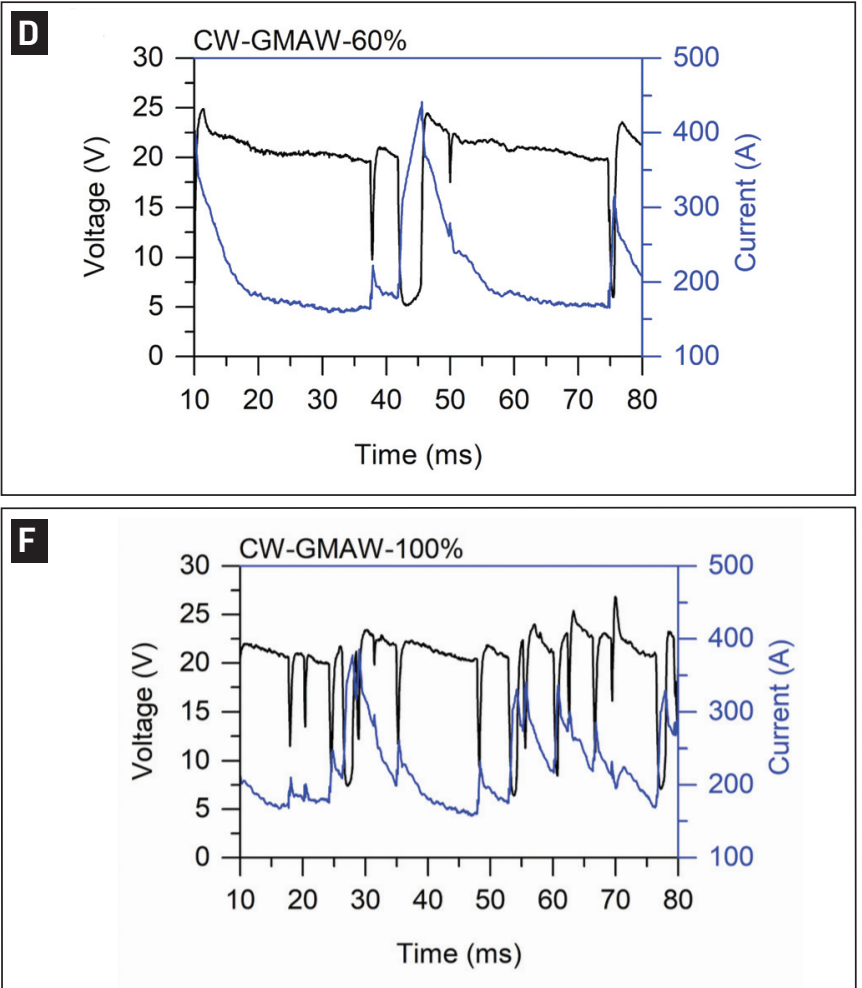

Fig. 3 - Oscillograms for short-circuit parameters. A - Standard GMAW; B - CW-GMAW-20\%; C - CW-GMAW-40\%; D - CWGMAW-60\%; E - CW-GMAW-80\%; F - CW-GMAW-100\%. It is important to remember that the percentages represent a mass fraction of the quantity fed by the main wire.

During the bead-on-plate welds, high-speed imaging was used to study the electric arc behavior with the following conditions: The high-speed camera was operated at a frame rate of 5000 frames/s, with an aperture of $f / 22$, and shutter speed of $25 \mu \mathrm{s}$. A narrow band pass filter of $900 \pm$ $10 \mathrm{~nm}$ wavelength reduced the amount of arc radiation reaching the camera sensor to resolve the drops clearly. In parallel, the electric signals were acquired using a data acquisition system with a frequency of $20 \mathrm{kHz}$ for $2 \mathrm{~s}$.

Table 2 - Parameters to Calculate the Melting Efficiency for the Bead Welds

\begin{tabular}{ccc}
$\eta_{\mathrm{a}}$ & $H_{\text {base }}\left(\mathrm{J} / \mathrm{mm}^{3}\right)$ & $H_{\text {fller }}\left(\mathrm{J} / \mathrm{mm}^{3}\right)$ \\
\hline 0.83 & $10.5^{(\mathrm{a})}$ & $7.88^{(\mathrm{b})}$ \\
\hline
\end{tabular}

(a) This value is for plain carbon steel according to Ref. 17 . (b) This value is for ER70S-6 according to Ref. 7
Figure 1 shows the general setup for the experiment. The cold wire in this experiment leads the arc and intersects with the electrode wire axis under the arc - Fig. 1B. The rationale for the cold wire leading the arc was based on observation during preliminary experiments that a trailing cold wire will interfere with arc stability and cause spatter for a wide range of parameters. To overcome this issue, the leading position was adopted for all subsequent experiments. The intersection position between the electrode wire and cold wire was determined during the preliminary experiments. When the two wires converged to a point under the arc (Fig. 1A), the spatter level was reduced, providing higher stability. One can see that the cold wire and the electrode wire are coplanar, sagittal to the plane of the workpiece Fig. 1B.

To calculate the droplet detachment frequency, high-speed videography provided equally spaced time intervals, and the droplet frequency could be manually counted for each test. 


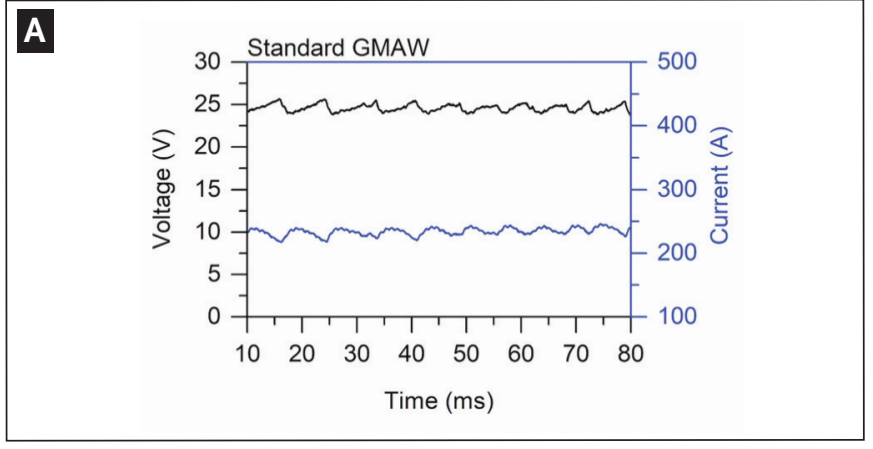

C



$\mathbf{E}$

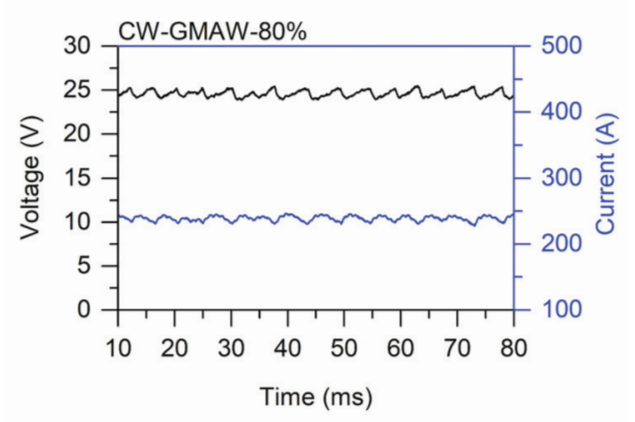

G

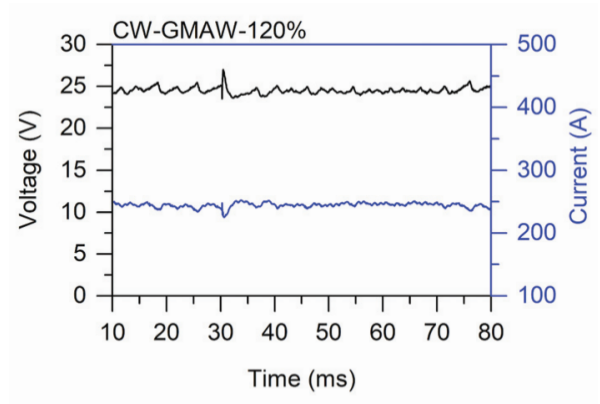

Fig. 4 - Oscillograms for globular parameters. A - Standard GMAW; B - CW-GMAW-20\%; C - CW-GMAW-40\%; D - CW-GMAW60\%; E - CW-GMAW-80\%; F - CW-GMAW-100\%; G - CW-GMAW-120\%; H - CW-GMAW-140\%. It is important to remember that the percentages represent a mass fraction of the electrode wire.

The results presented are an average of five values (five time intervals). To calculate the droplet diameter, Equation 1 was used based on the proposed relation (Ref. 15):

$$
D_{d}=\left(\frac{W F S d_{e}^{2}}{40 f_{d}}\right)^{\frac{1}{3}}
$$

where WFS is the wire feed speed in units of in./min, $d_{e}$ is
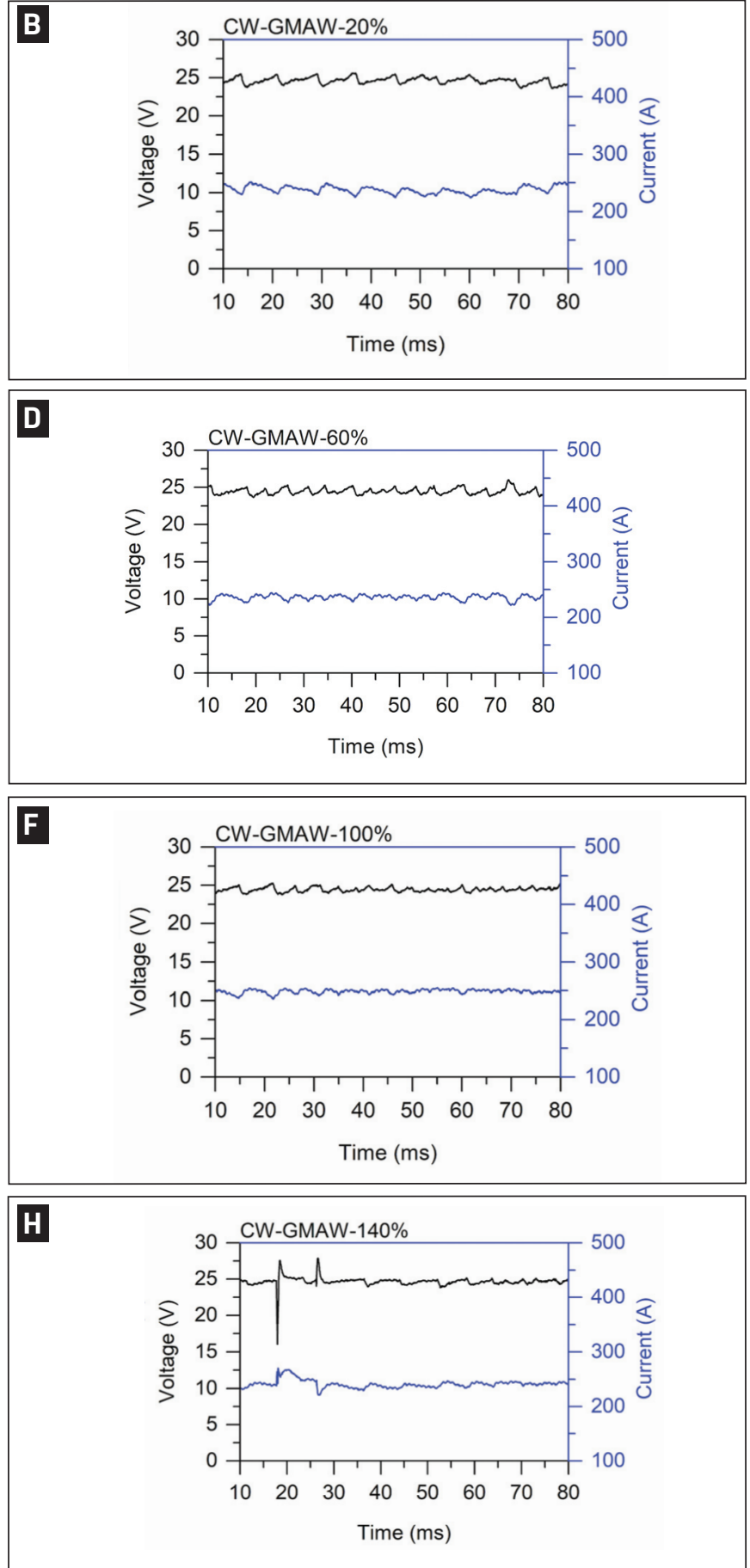

the electrode diameter in inches (in.), and $f_{d}$ is the detachment frequency (in units of $\mathrm{Hz}$ ).

To assess the influence of cold wire in current variation for each transfer mode, each welding condition was replicated eight times, and the values of instantaneous current were recorded and statistically treated. The results present the average instantaneous current with a variation of $95 \%$ confidence levels (Ref. 16).

After welding, the beads were cross sectioned and prepared 


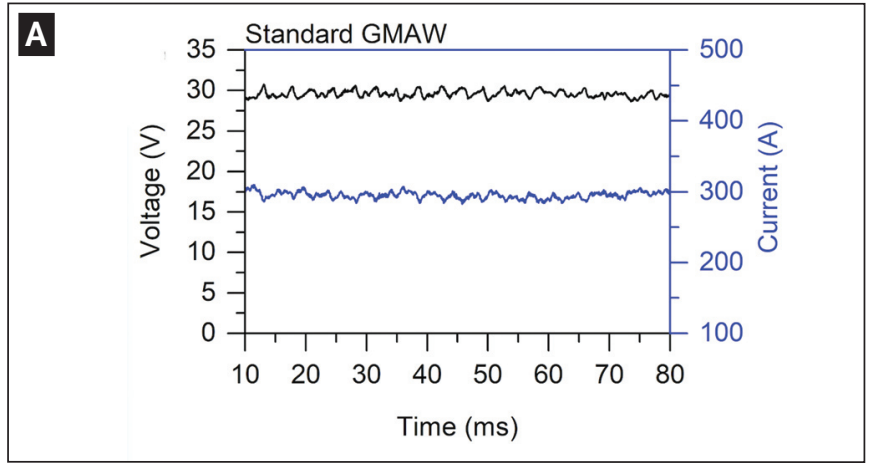

C

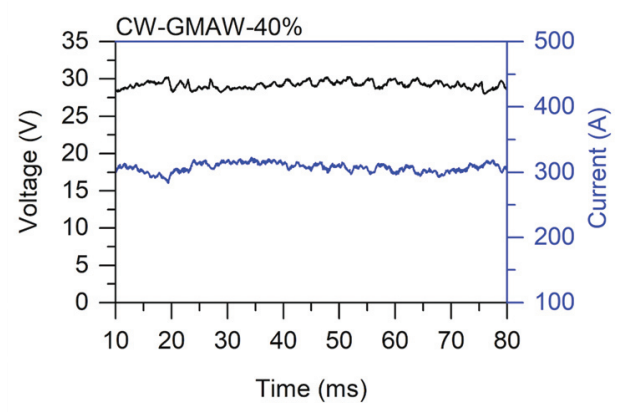

$\mathbf{E}$

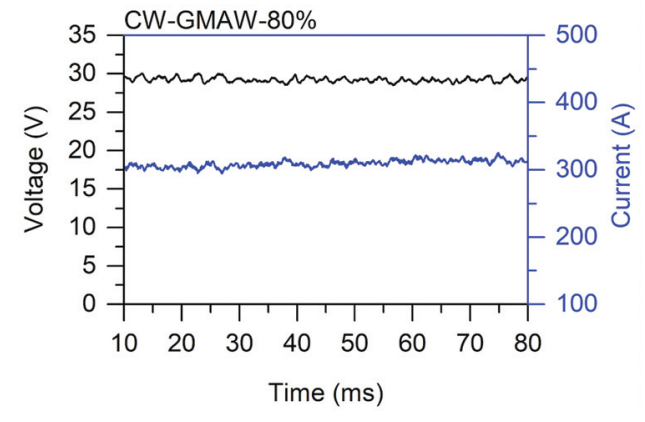

G

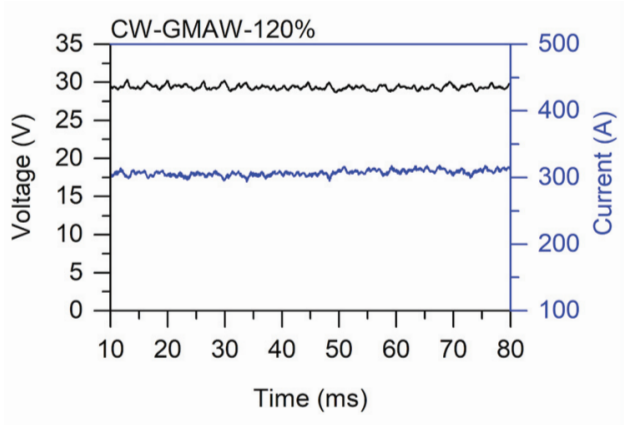

Fig. 5 - Oscillograms for the spray parameters. A - Standard GMAW; B - CW-GMAW-20\%; C - CW-GMAW-40\%; D - CW-GMAW60\%; E - CW-GMAW-80\%; F - CW-GMAW-100\%; G - CW-GMAW-120\%; H - CW-GMAW-140\%. It is important to remember that the percentages represent a mass fraction of the main wire.

through standard metallographic procedures and etched with Nital $5 \%$ to show the macrostructure of the cross sections and allow the measurement of geometrical features such as penetration, height, and width. Subsequently, the melting efficiency and dilution were calculated, refer to Equations 2 and 3, respectively, based on the schematic provided in Fig. 2. Generally, the arc efficiency $\left(\eta_{a}\right)$ is defined as the ratio between the

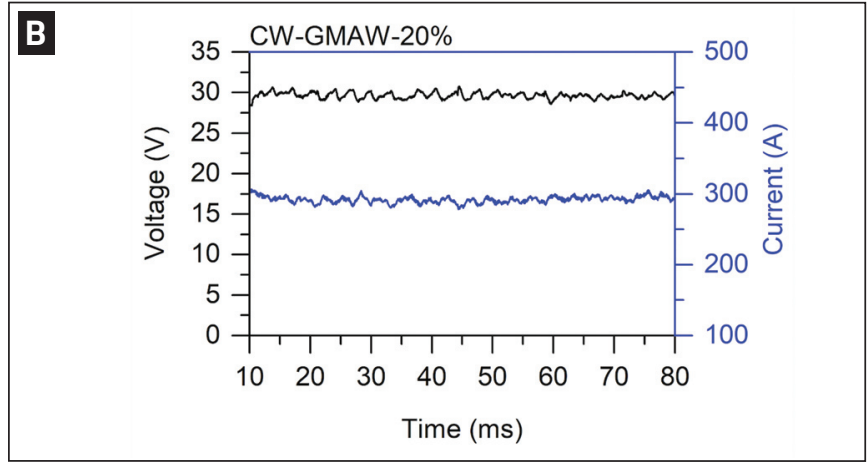

D

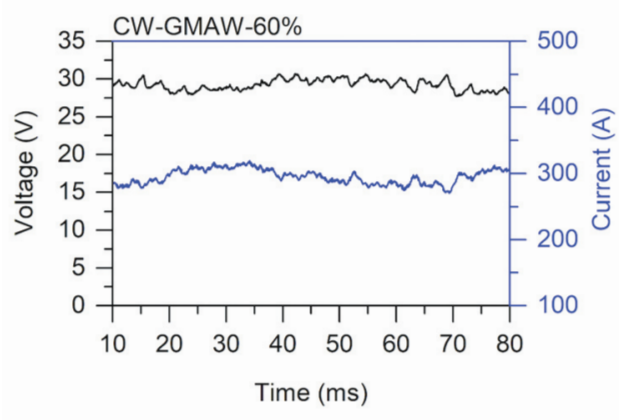

$\mathbf{F}$



H

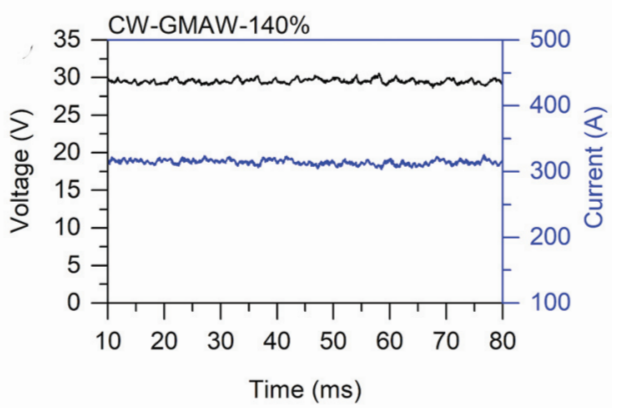

heat transferred to the welded part and the net arc heat input delivered by the arc (Ref. 17). In this work, it is assumed that the GMAW and CW-GMAW arc efficiencies are the same. The shielding gas composition used was $\mathrm{Ar}-15 \% \mathrm{CO}_{2}$ at the flow of $40 \mathrm{ft}^{3} / \mathrm{h}$ (18.871/mn). Table 2 gives the thermophysical properties used to calculate melting efficiency $\left(\eta_{\mathrm{m}}\right)$. Dilution is first calculated based on 


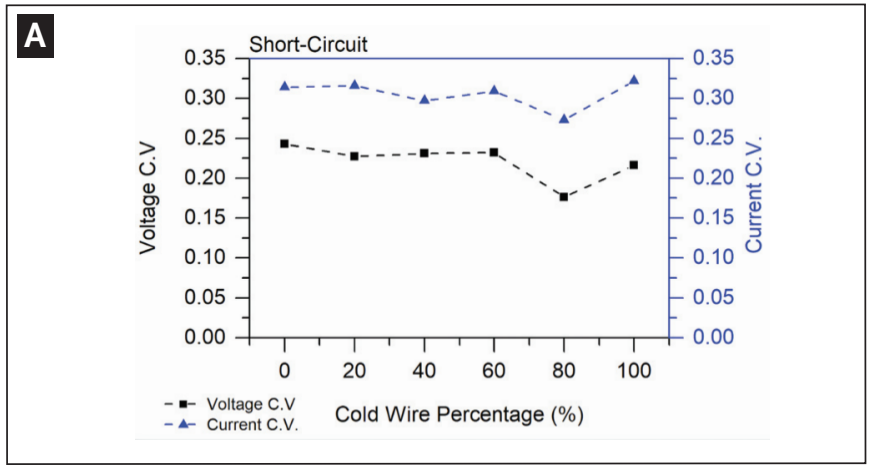

$$
D(\%)=\left(\frac{A_{\text {base }}}{A_{\text {base }}+A_{\text {filler }}}\right) \times 100 \%
$$

where $A_{\text {filler }}$ is the cross-sectional area $\left(\mathrm{mm}^{2}\right)$ due to the filler metal, and $A_{\text {base }}$ is the area $\left(\mathrm{mm}^{2}\right)$ due to the base metal. The melting efficiency is then calculated using the proposed relation by Ref. 7:

$$
\eta_{m}=\frac{\left(A_{\text {base }} V t_{\text {weld }}\right) H_{\text {base }}+\left(A_{\text {filler }} V t_{\text {weld }}\right) H_{\text {filler }}}{\eta_{a} U I t_{\text {weld }}}
$$

where $H_{\text {base }}$ and $H_{\text {filler }}$ are the volumetric enthalpy of the base and filler metals $\left(\mathrm{J} / \mathrm{mm}^{3}\right), t_{\text {weld }}$ is the welding time in seconds (s), $V$ is the travel speed $(\mathrm{m} / \mathrm{s}), \eta_{a}$ is the arc efficiency, $U$ is the arc voltage $(\mathrm{V})$, and $I$ is the arc current in $A$.

To calculate the cold wire absorbed power, which represents how much of the arc power the cold wire is able to absorb depending on each condition, Equation 4 was used. The wire physical quantities employed in the calculation are given in Table 3. The absorbed heat by the cold wire was calculated as a sum of the specific and latent heat of the additional wire, excluding the vaporization of the liquid that requires

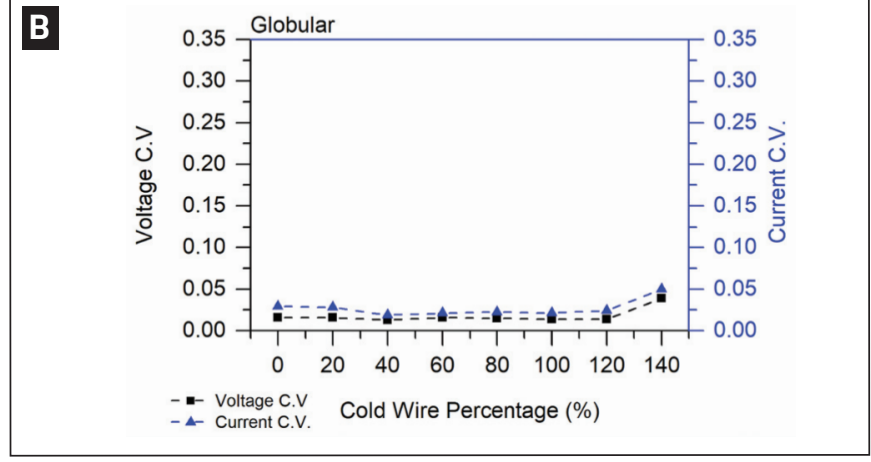

C

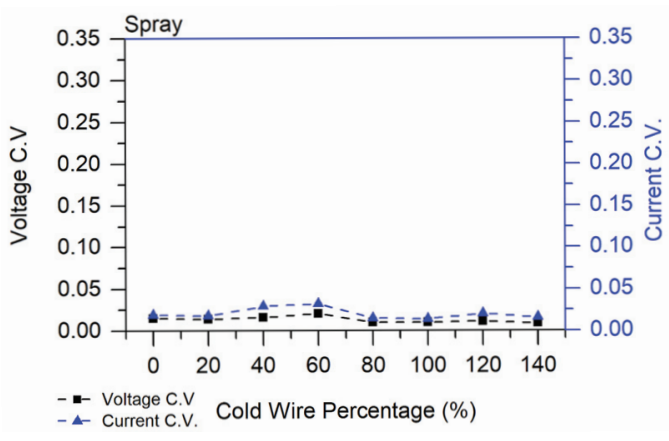

Fig. 6-Coefficient of variation (CV) for all the three natural transfer modes in welding, for each cold wire feeding condition.

the consideration of energy for heating to vaporization and change from the liquid state to gas. The value of this absorbed heat is given by

$$
\dot{Q}=\dot{m} c_{s} \Delta\left(T_{m}-T_{o}\right)+\dot{m} L
$$

where $Q$ represents the cold wire absorbed power in $\mathrm{kW} ; \dot{m}$ represents the cold wire mass feed rate in $\mathrm{kg} / \mathrm{s} ; c_{s}$ is the solid specific heat in $\mathrm{kJ} / \mathrm{kg} ; T_{m}$ and $T_{0}$ are the wire melting tempera-

Table 3 - Physical Constants of the Wire Used ER70S-6 in the Electrode and Cold Wire

\begin{tabular}{lcccccc}
$\begin{array}{c}\mathrm{D}_{\text {electrode }} \\
(\mathrm{mm}) \\
{[\mathrm{in} .]}\end{array}$ & $\begin{array}{c}\mathrm{D}_{\text {cold wire }} \\
(\mathrm{mm}) \\
{[\mathrm{in}]}\end{array}$ & $\begin{array}{c}\text { Density } \\
(\mathrm{kg} / \mathrm{m})\end{array}$ & $\mathrm{C}_{\mathrm{s}}(\mathrm{kJ} / \mathrm{kg} \mathrm{K})$ & $\mathrm{L}(\mathrm{kJ} / \mathrm{kg} \mathrm{K})$ & $\mathrm{T}_{\mathrm{m}}(\mathrm{K})$ & $\mathrm{T}_{0}(\mathrm{~K})$ \\
\hline $1.2[0.045]$ & $0.9[0.035]$ & 7930 & 0.70 & 200 & 1723 & 293 \\
\hline
\end{tabular}

Table 4-Welding Parameters Set in the Source for All the Transfer Modes

Short Circuit

Wire feed speed (in./min) [m/min] $250(6.35)$
Voltage $(\mathrm{V})$

20

Globular

Wire feed speed (in./min)

250
Voltage (V)

25
Travel speed (in./min) [cm/min] 25 (63.5)

Travel speed (in./min)

25

\section{Spray}

Wire feed speed (in./min) $[\mathrm{m} / \mathrm{min}]$ 350 (8.89)

Voltage (V)

30
Travel speed (in./min)

25 


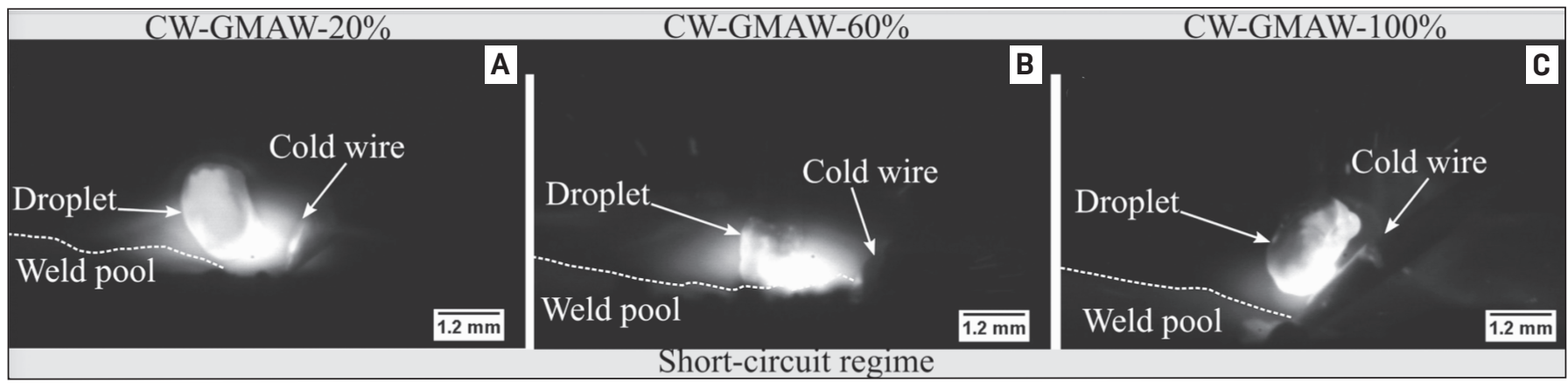

Fig. 7 - The climbing of the arc in the cold wire for the short-circuit condition. $A-20 \%$ of cold wire; B $-60 \%$ of cold wire; $C-$ $100 \%$ of cold wire.

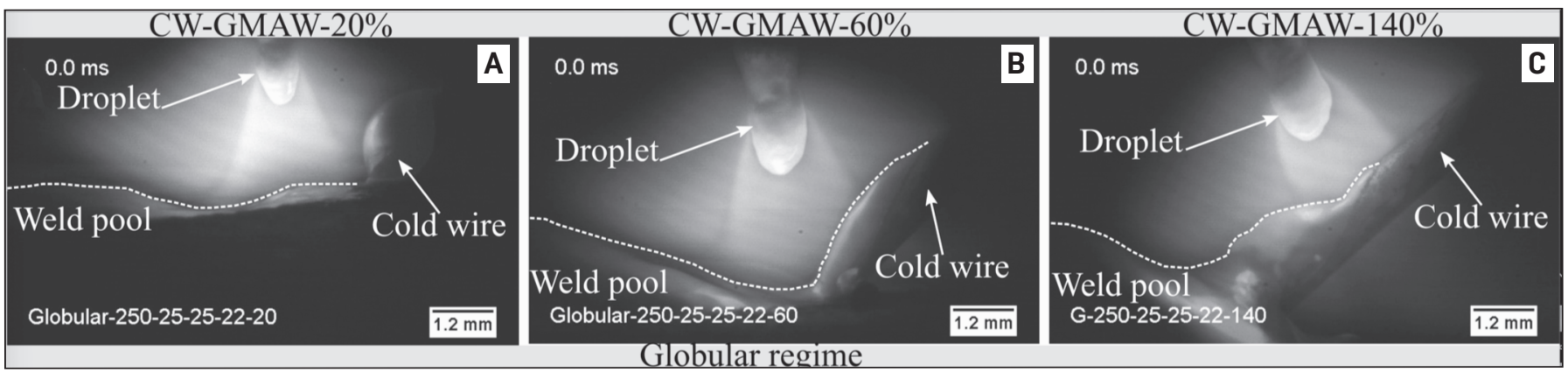

Fig. 8 - The deflection of the arc in the cold wire for the globular condition. A - 20\% of cold wire; B - 60\% of cold wire; C $140 \%$ of cold wire.

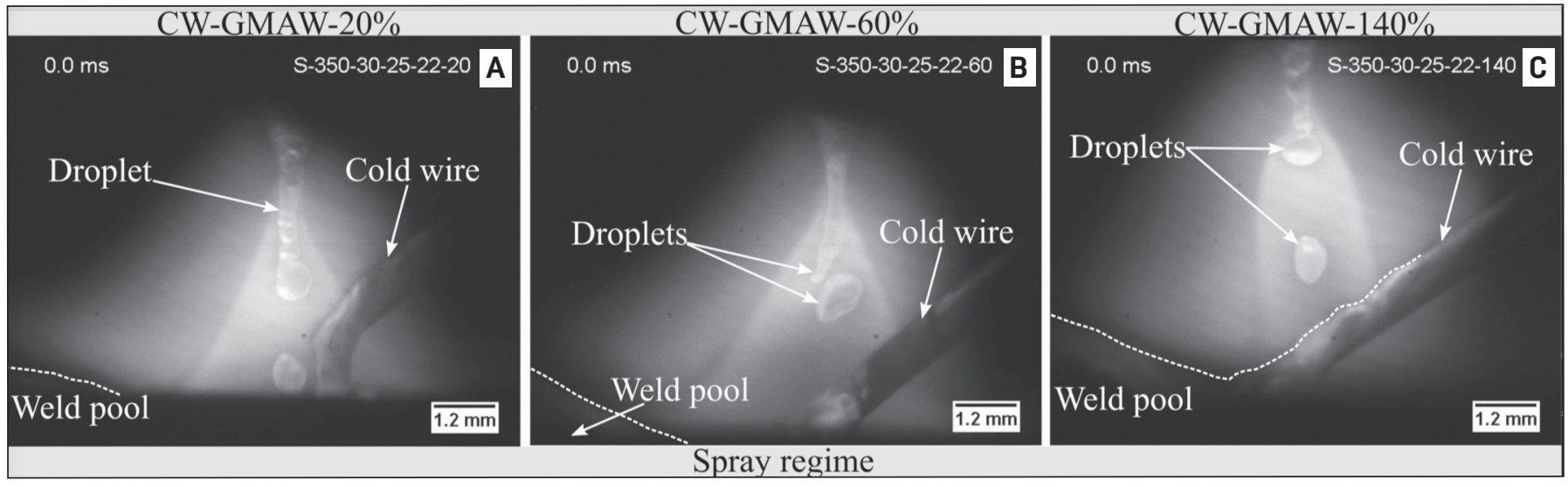

Fig. 9 - The deflection of the arc in the cold wire for the spray condition. A-20\% of cold wire; B - 60\% of cold wire; $C-140 \%$ of cold wire.

ture and the room temperature, respectively, in Kelvin; and $L$ is the wire latent heat in $\mathrm{kJ} / \mathrm{kg}$.

Table 4 summarizes the parameters used in the welding source, for the three intended transfer modes, for the welds in this work. For all the welds in this work, the contact tip to workpiece distance is kept equal to $22 \mathrm{~mm}$. Further details concerning the experimental setup can be found in prior work (Ref. 11).

\section{Results}

\section{Electrical Signals and Arc Stability}

Figure 3 presents the oscillograms for the short-circuit conditions. One observes the presence of incipient short circuits (by definition those with duration $<2 \mathrm{~ms}$ ). As the cold wire is in contact with the substrate, it can short circuit the droplet being formed. The distance to the droplet is less than to the workpiece, which explains the increase of short-circuit frequency as the cold wire fraction is increased, leading to more spatter formation.

Figure 4 shows the oscillograms when globular conditions are used during CW-GMAW. One can note that in contrast to the short-circuit case, the introduction of the cold wire is better accommodated here, which can be explained by the higher energy available in the weld pool. In fact, this allowed the introduction of more than a $100 \%$ mass ratio of cold wire to the electrode wire.

Figure 5 presents the electrical data for the spray condition. In this condition, even higher energy is available in the system 
A

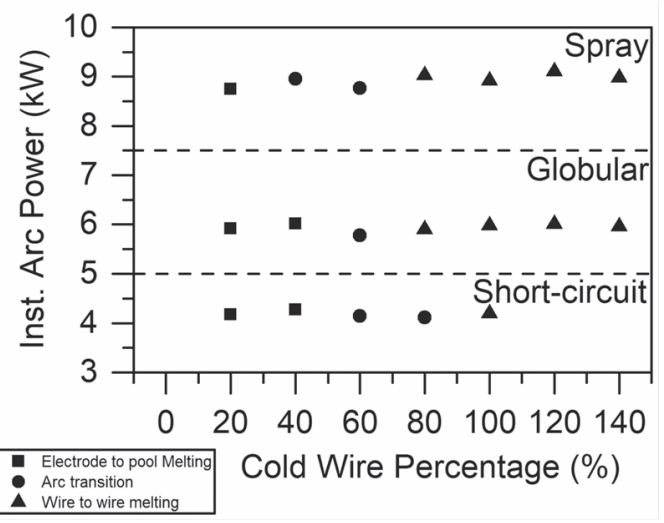

B

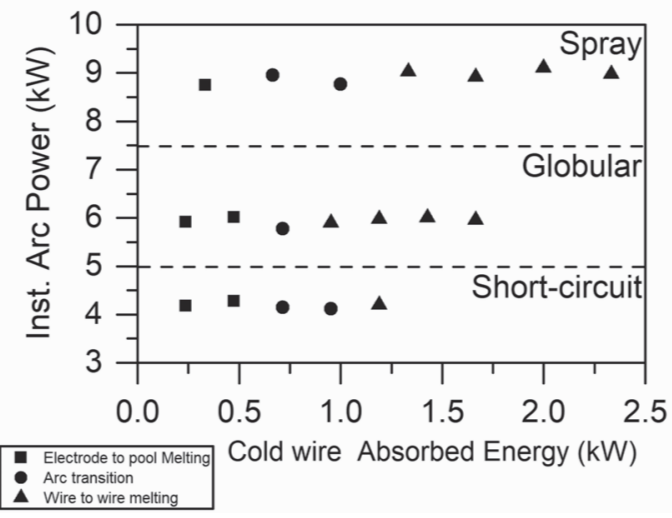

Fig. 10 - The influence of cold wire percentage feeding and absorbed energy in arc instantaneous power. A - Arc power vs. cold wire feeding; $B$ - arc power vs. cold wire absorbed power.

arc melt pool, allowing higher amounts of cold wire to be fed compared to the short-circuit (low energy) condition. This time, all incipient short circuits are avoided, meaning cold wire feeding is better accommodated. For these particular parameters, it was possible to only reach a $140 \%$ cold wire mass contribution rate, where higher values led to pronounced spatter.

Figure 6 shows a quantitative analysis of arc stability based on the coefficient of variation (CV) of voltage and current, a statistic accounting for the variation of a particular quantity; lower values of CV represent stable conditions. In the short-circuit regime, the CW-GMAW process results in higher CV, except for the $80 \%$ and $100 \%$ cold wire feed conditions that have CV approximately equal to standard GMAW. As for the globular and spray regimes, as said, the introduction of cold wire does not induce significant disturbances in the arc.

One observes that progressively more arc attachment to the cold wire occurs as its feed rate increases in the shortcircuit regime - Fig. 7. The distance of cold wire to the droplet is lower than to the weld pool, which causes the droplet to short circuit with the cold wire, since this is in contact with the cathode (substrate), explaining the amount of spatter - Fig. 7C.

Figures 8 and 9 show the progressive deflection of the arc to the cold wire as the cold wire mass fraction is increased for the globular parameters and spray, respectively. One observes that the arc length decreases for higher cold wire feed rates in globular mode while it is constant in spray.

As briefly described previously, the increase of cold wire fraction is perceived by the source as an increase in the electrode wire feed speed, which causes an increase in current to balance the melting rate to achieve a stable mass transfer through the arc. For instance, standard GMAW achieves an average current of $299 \mathrm{~A}$ in spray regime, while CW-GMAW at the rate of $140 \%$ demanded approximately $321 \mathrm{~A}$, or an average increase of $22 \mathrm{~A}$.

Clearly, the difference where the cold wire is melted implies a difference in the cold wire absorbed power, which is the heat generated by the electric arc that can be absorbed by the cold wire and redrawn into the arc weld pool.

Figure 10A presents the instantaneous arc power vs. the cold wire percentage for the three different welding sets of pa- rameters taking into account the position of the arc in relation to the cold wire. The transition in arc attachment is clear for the different cold wire feed rates, along with the amount that can be fed to keep a determined position of the arc to the cold wire. For instance, as the arc power increases, there is a trend to the arc move to the cold wire as well as the melt pool.

Figure $10 \mathrm{~B}$ shows the arc power vs. the cold wire absorbed energy, revealing that the position of the arc related to the cold wire dictates how much power will be absorbed. For instance, the wire to wire melting position enables more power to be transferred than any other arc position relative to the cold wire position. In future sections, the relationship between arc position related to the cold wire vs. dilution and melting efficiency will be discussed.

Figure 11 shows the current variation for all the conditions studied in this paper, as mentioned in the introduction, while prior research has shown that there is an increase of current for CW-GMAW. The data revealed that this increase in current is statistically significant only for the globular and spray conditions. For instance, in the globular transfer mode case (Fig. 10B), there is a statistical difference between the standard GMAW and the CW-GMAW only for cold wire feed rates of $>40 \%$. The same can be said for the case of spray transfer, meaning only the cold wire feed rates higher than $40 \%$ led to notable features in the arc.

\section{Detachment Frequency and Droplet Size}

Figure 12A shows the droplet diameter in short circuit, and Fig. 13A shows the short-circuit frequency for all the cold wire feedings. One can note that droplet diameter and frequency are inverse quantities. The results indicate the diameter of the droplets increase on average, and, consequently, the short-circuit frequency decreases. This is consistent with the observation that arcing time in the short-circuit mode increases as the number of short circuits decreases, for certain conditions, as observed in the previous section titled "Electrical Signals and Arc Stability."

Figure 12B shows the droplet diameter, and Fig. 13B shows the droplet detachment for the globular case. Contrary to the expectations, the data does not indicate any trend, suggesting that the droplet diameter and detachment 

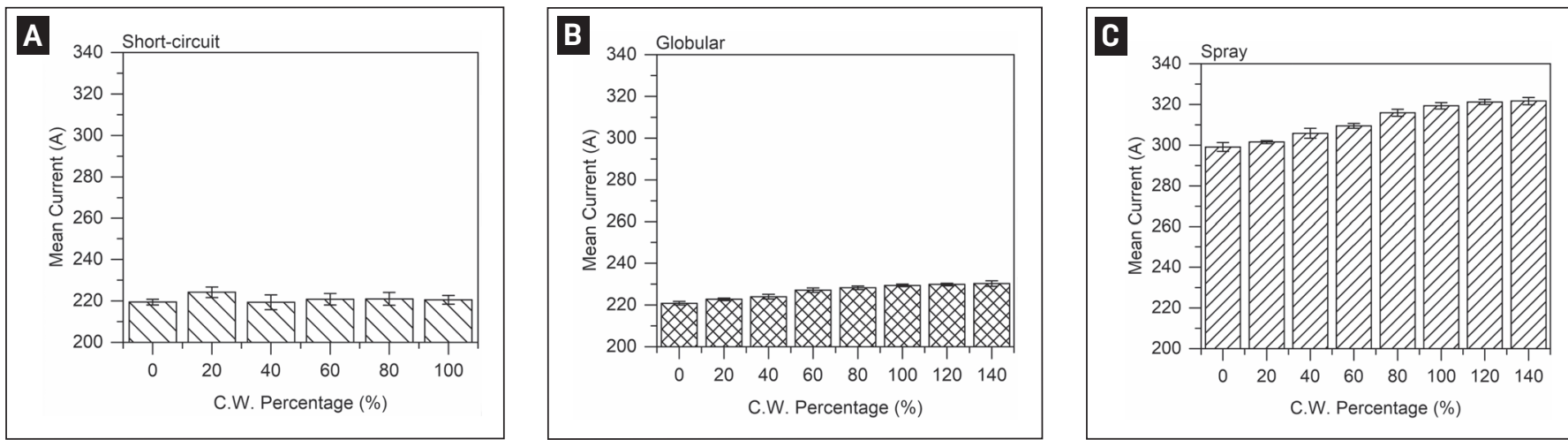

Fig. 11 - Current variation for all the transfer modes. A - Short-circuit; B - globular; C - spray.
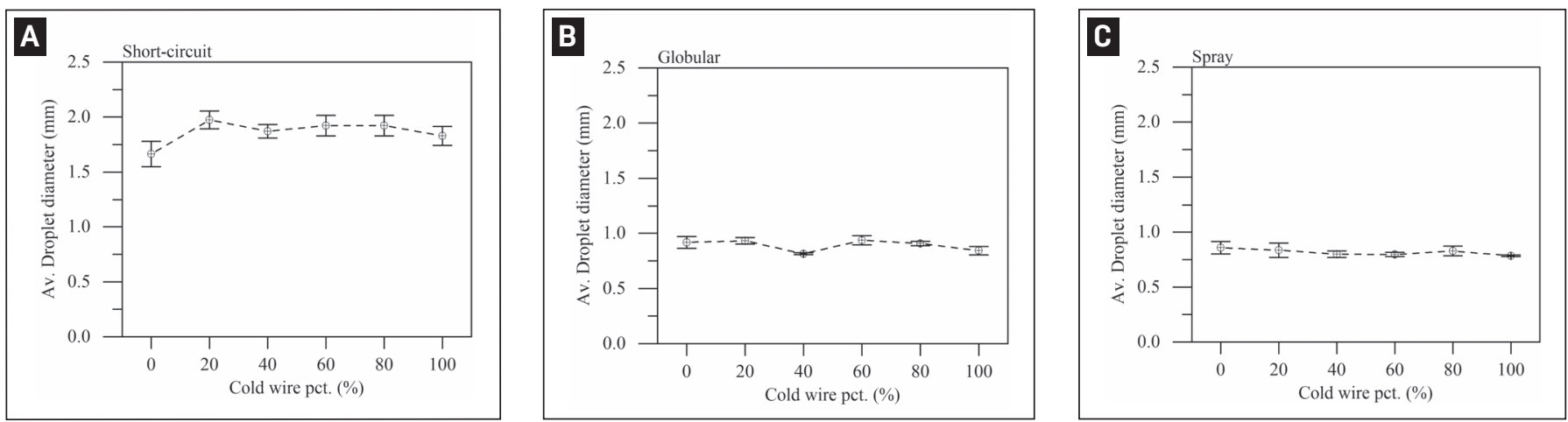

Fig. 12 - Droplet diameter. A - Short circuit; B - globular; C - spray.

frequency are lower than others. The reason behind this erratic behavior remains unclear.

Figure $12 \mathrm{C}$ shows the droplet diameter, and Fig. $13 \mathrm{C}$ shows the droplet detachment frequency for spray. One observes the decrease in droplet diameter and an increase in frequency, which leads to the increase of spray detachment frequency. The variation in electrode current (Fig. 11C) indicates that for this transfer, there is a trend toward the increasing of current with CW feed rate, indicating a proportional increase in electromagnetic force, which explains the increase in the detachment frequency.

\section{Cross Sections and Bead Geometry}

The variation in the size of the droplet shown in the previous section led to a change in the geometry of the cross section geometric features of the resulting beads. Figure 14 shows the cross section for the short-circuit case. One observes that as the cold wire feed rate increases, the height of the bead increases, meanwhile the dilution decreases. This can be thoroughly revealed in Fig. 17C based on the average values of bead height with CW feed rate, and Fig. 18A where dilution measurements are reported. One finds that this trend is observable for all the welding conditions, and so it is important to determine which transfer mode is more sensitive to the height increase.

Figure $17 \mathrm{C}$ shows that bead height increases faster for globular than for other metal transfers. A possible explanation for this is that short circuit leads to spatter, which reduces the amount of metal deposited when this becomes excessive. In contrast, for spray, the existence of metal evapo- ration and spatter inhibits the increase of bead height.

Figures 15 and 16 show the cross sections for the globular and spray case, respectively. Comparing them with Fig. $17 \mathrm{~A}$, one sees that the penetration decreased with the increase in cold wire feed rates, contrary to the typical behaviour with standard GMAW, which dictates that depth of penetration increases with current (Ref. 18). Although, as seen in Fig. 11, when there is an increase in current, which is highest during spray transfer, the penetration decreases.

Figure 17B shows the variation of width for the transfer modes under study here. One sees that for short-circuit transfer the cold wire has almost no influence on bead width, since the values reported seem statistically equal. The same trend is observed for globular. In contrast, only for two spray conditions ( $40 \%$ and $60 \%$ cold wire feed rates) is there a significant difference from the standard GMAW, which suggests that the cold wire has an influence on bead width in this condition.

One can also see from the cross sections that short circuit (Fig. 14) the wetting angle, defined as the angle between the substrate and the edge of the bead, it is not excessively high, suggesting poor wetting. Consequently, the weld beads are sound, and defects such as incomplete fusion or inclusions are unlikely to form.

One can also note that similar to the globular case (Fig. 15), there were no inclusions, incomplete fusion, or porosity found in the cross sections. Moreover, the height in globular transfer is slightly higher than in other transfer modes, along with the lowest dilution. These suggest the globular parameter to be particularly well suited to weld surfacing.

The cross sections in spray (Fig. 16) also do not present 
A

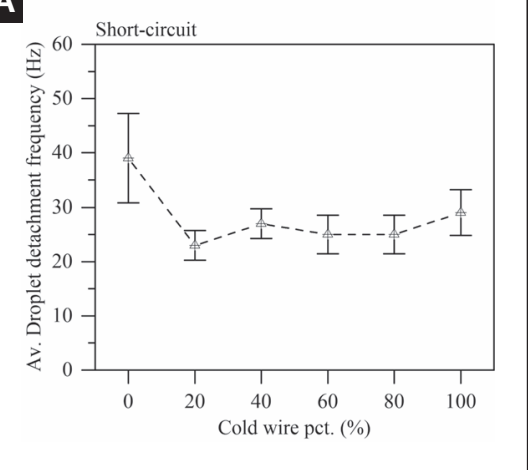

B

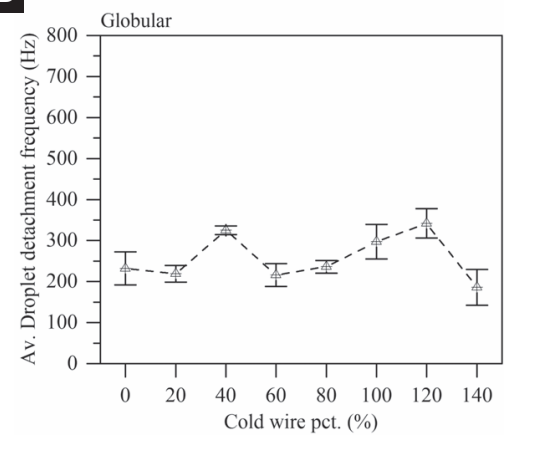

C

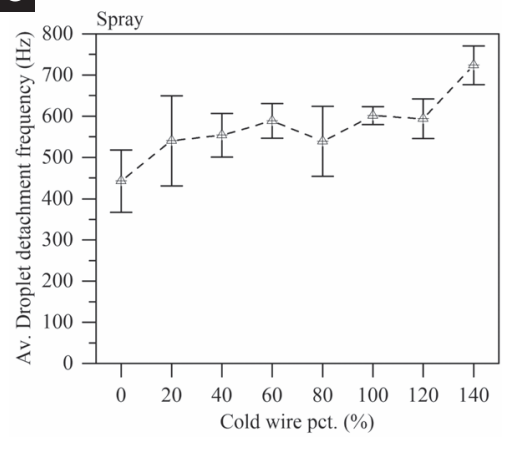

Fig. 13 - Droplet detachment frequency. A - Short circuit; B - globular; C - spray.

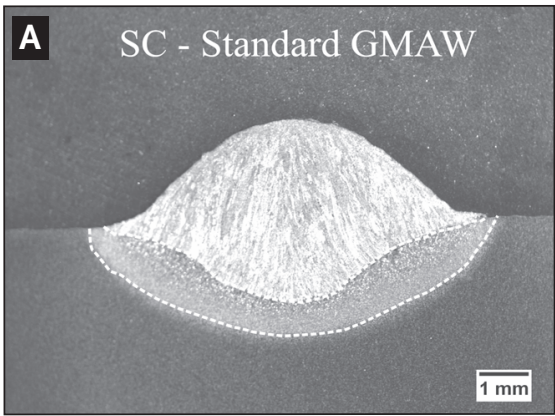

D

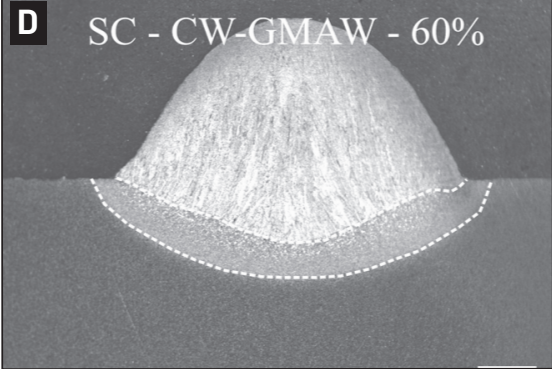

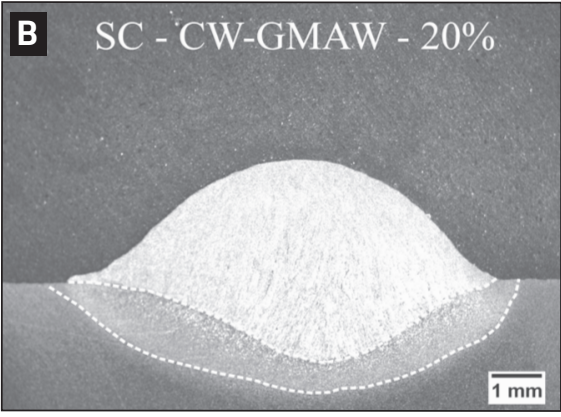

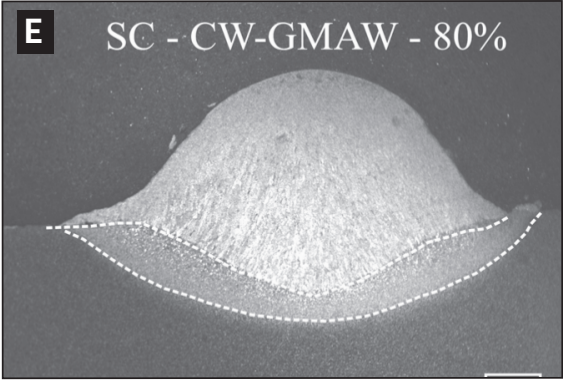

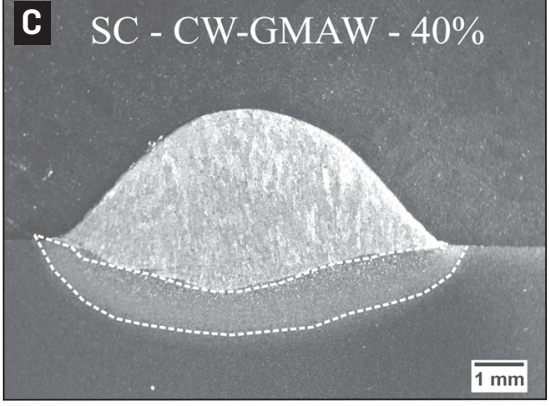

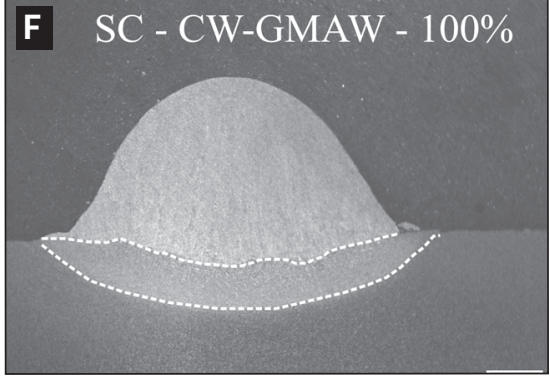

Fig. 14 - Cross sections for short-circuit conditions. SC indicating the transfer mode (short circuit) and the percentage indicating the quantity of cold wire, when the case.

discontinuities such as porosities, incomplete fusion, or inclusions. One remarkable feature they possess is the fingerlike penetration. This type of penetration is normally expected for welds performed in spray transfer. This is due to the momentum of the axial droplets in the weld pool. One observes that the increase of cold wire mass feeding decreases the finger-like penetration. This is likely due to the shielding effect of the cold wire when the arc is pinned to it.

\section{Dilution and Melting Efficiency}

The changes in metal transfer caused by increasing the cold wire feed rates ultimately caused a change in dilution and in melting efficiency since both are related, as pointed out by the seminal work of DuPont and Marder (Ref. 19).

Figure 18A presents the dilution values for the three different welding modes: short circuit, globular, and spray. Each bar center signifies the average, with the standard deviation represented by the whiskers for each cold wire feed rate condition. One observes that the general trend indi- cates that dilution decreases with increasing cold wire feed rate, which is explained by the increase of mass deposited that causes an increase in the filler metal area at the expense of the base metal area of the bead (Equation 2). This decrease of dilution for higher cold wire feed rates ultimately means that for high values of cold wire feed, there is less base metal dilution in the deposited bead. This situation is also desirable for weld surfacing as a potential application of the CW-GMAW process.

Figure $18 \mathrm{~B}$ presents the melting efficiency for the three welding modes for all the cold wire feeding rates. The dashed line represents the theoretical melting efficiency of arc welding processes based on the equation proposed by Fuerschbach and Knorovsky (Ref. 17), which is 0.5 .

One can discern that for globular and spray transfer, there is a clear increasing trend between melting efficiency and cold wire feeds. This is due to an increase in the filler metal area contributed by the cold wire feeding, which consequently increases the numerator of Equation 3. This increases the apparent melting efficiency under the general 

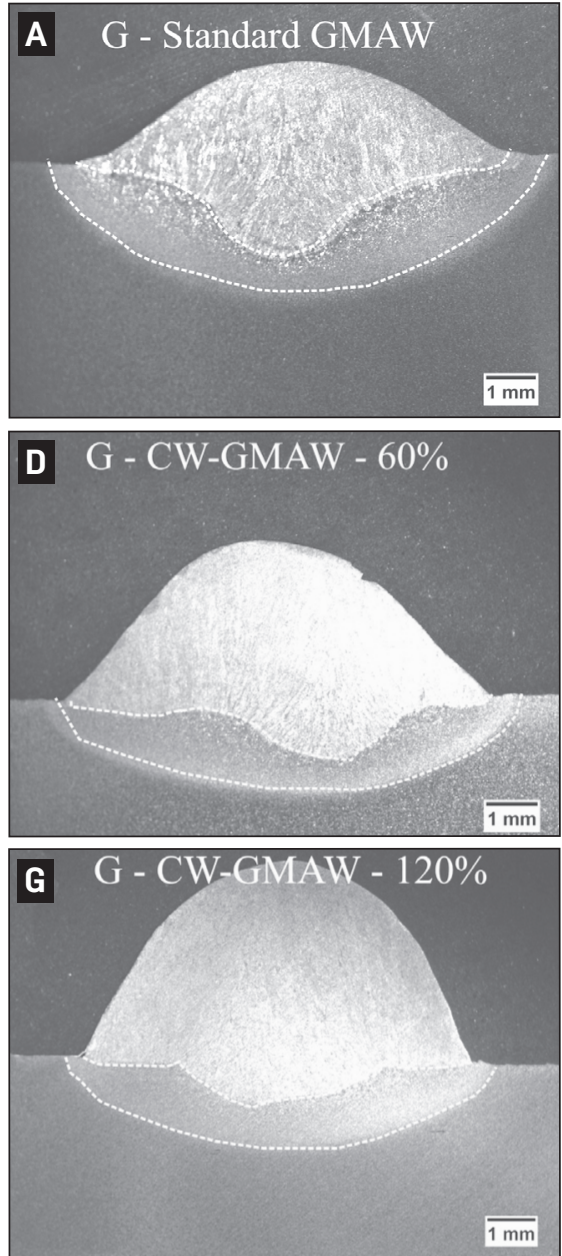
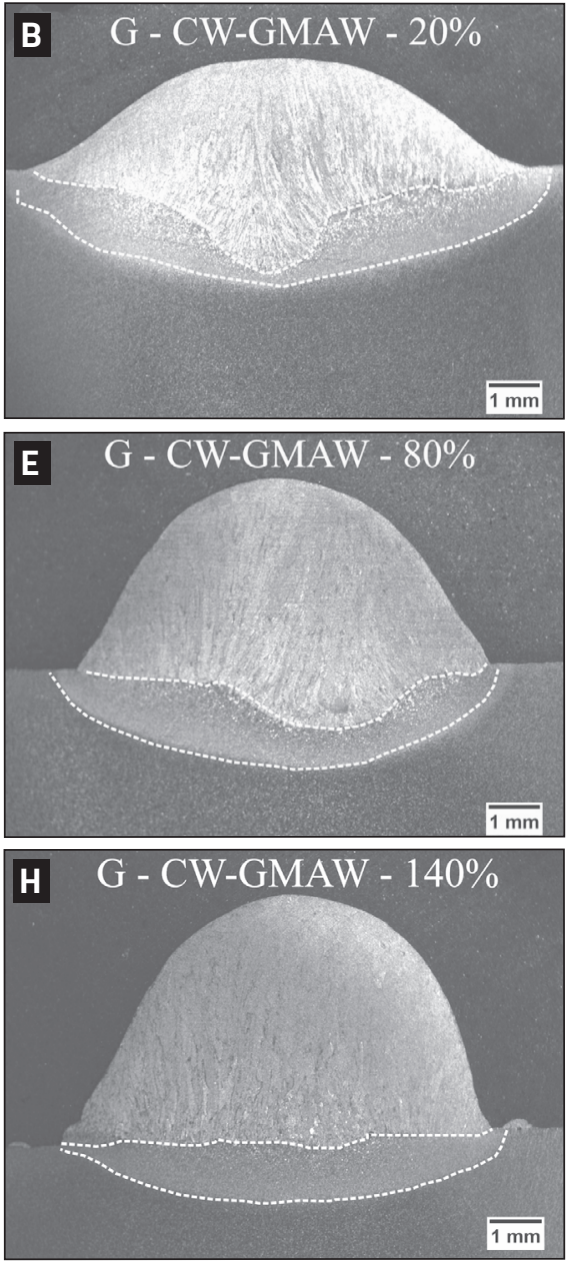

Fig. 15 - Cross sections for short-circuit conditions. G indicating the transfer mode (globular) and the percentage indicating the quantity of cold wire, when the case.

hypothesis that cold wire feeding does not significantly alter the arc efficiency of gas-shielded arc welds.

For one situation at the highest cold wire feed rate with globular transfer, the melting efficiency of the CW-GMAW welds exceeded the theoretical limit proposed by Fuerschbach and Knorovsky (Ref. 17), suggesting that the CWGMAW can impart a greater part of the energy delivered by the arc to the workpiece than actually used to melt the filler and base metals.

\section{Discussions}

\section{Oscillograms and Arc Stability}

The oscillograms in globular and spray indicate higher levels of arc energy, which creates a hotter weld pool. Consequently, it can accommodate higher fractions of cold wire feed rates (\% in mass). For instance, it seems that the energy of the arc-weld pool set plays a key role on process stability causing the $\mathrm{CV}$ to decrease in globular and spray transfer regimes.

Regarding the short-circuit regime, one can discern that in some cases, the cold wire extends the arc period between droplet formation and short circuiting. This is readily ex-
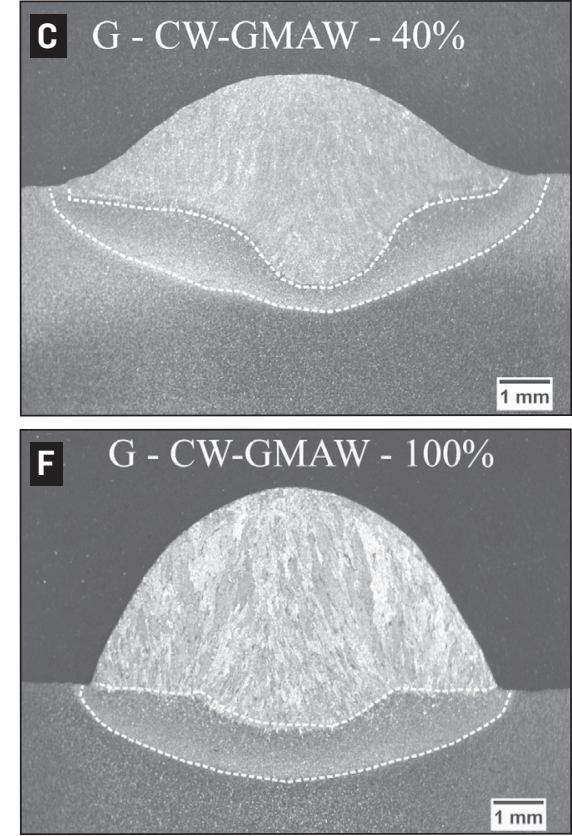

plained by the fact the arc must melt a larger mass, when cold wire is introduced, to form the droplet, which needs more time to detach the droplet considering the standard GMAW condition.

It is likely that the power source operation based on constant voltage regulation accounts for the increase in current with wire feed speed (in./min), and consequently, an increase in electrode wire melting rate for these transfer modes to maintain the voltage set point in the power source. Consequently, metal transfer becomes more stable, avoiding the phenomenon of arc climb to the contact tip described by Zhang et al. (Ref. 20), which disturbs the arc and may cause its extinction.

\section{Metal Transfer Mechanisms and Arc Position Regarding the Cold Wire}

During welding, it was observed that the arc attachment changes to the cold wire, independently of the welding transfer condition, as the cold wire is fed into the weld pool. It was possible to distinguish three main positions:

1) Electrode to pool melting: The arc retains its straight position and the cold wire is melted inside the arc. Generally, this condition is observed for cold wire feeding rates of $<60 \%$;

2) Arc transition: This condition shows a transition in the arc position; the arc starts to climb the cold wire, but remains pinned to the workpiece. This condition generally happens for cold wire feed rates between 60 and $80 \%$;

3) Wire to wire melting: In this condition, the arc is completely pinned to the cold wire, meaning that the weld pool was displaced to the cold wire. This condition happens for cold wire feed rates $\geq 100 \%$.

Figure 19 shows schematically the positions of the arc position in relation to the cold wire as a function of different 

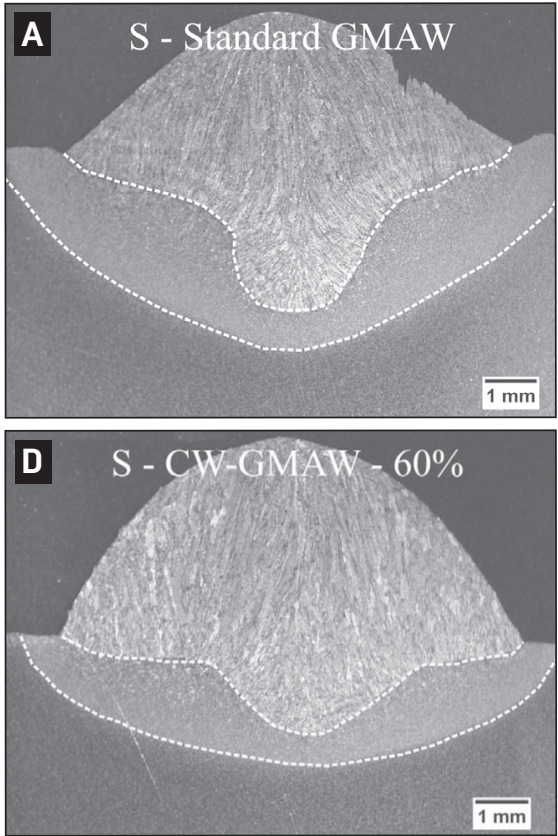

cold wire feed rates. This change in the arc trajectory could be explained by two effects, namely, the natural electron path and arc blow. The natural electron path effect related to the current flow in the sense of lower resistance (shortest path). The arc blow is caused by the presence of a transverse magnetic field. It is believed that the change in arc direction is due to the lower resistance offered by the cold wire to pin the arc. Further details concerning this mechanism are given by Zhang et al. (Ref. 20), which discusses this mechanism, particularly in relation to the arc attachment to the sidewalls in narrow grooves.

The increase in cold wire feed rates, as discussed, causes the displacement of the arc. One can expect that this increase in cold wire feed rates will affect the electrical response, and an increase in current was noted. More details will be provided in the next section.

\section{Current Variation and Electromagnetic Force}

The variation in current was noticed to be statistically significant only for globular and spray transfer regimes for cold wire feed rates higher than $40 \%$. The rationale for the nonsignificance in short-circuit regime might be linked to the constant voltage regulation of the source, which allows increasing of the arcing period but restricts the variation of current to keep the transfer mode in short circuit. For globular and spray regimes, there is more room for current variation without a change of transfer mechanism.

Once the cold wire feed rate reaches $40 \%$, the current increases significantly compared to the conventional GMAW condition for globular and spray regimes. This current increase also entails a variation of electromagnetic force. Amson (Ref. 21) studied the electromagnetic force $\left(F_{e m}\right)$ to which droplets are subjected. This force is correlated to cur-
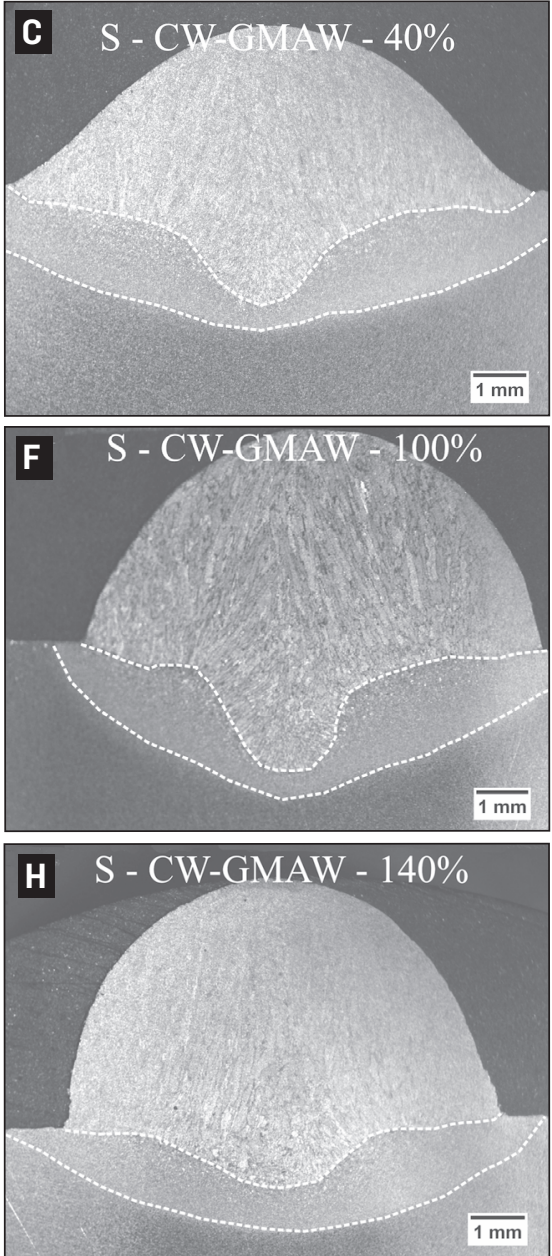

$\overline{1 \mathrm{~mm}}$

$\overline{1 \mathrm{~mm}}$

Fig. 16 - Cross sections for short-circuit conditions. S indicating the transfer mode (spray) and the percentage indicating the quantity of cold wire, when the case.

rent square $\left(I^{2}\right)$ by Equation 5 . Here, $\mu_{0}$ is the magnetic permeability of the medium that is equal to $12.6 \times 10^{-7} \mathrm{H} / \mathrm{m}, D_{d}$ is the droplet diameter, $r$ is electrode radius, and $\theta$ is the arc root angle while $f\left(D_{p}, r, \theta\right)$ is a function that can be solved based on the assumed morphology of the drop.

$$
F_{e m}=\frac{\mu_{0} I^{2}}{4 \pi} f\left(D_{d}, r, \theta\right)
$$

assuming that $f\left(D_{p}, r, \theta\right)$ is constant for conventional GMAW and CW-GMAW conditions, and taking the spray regime as an example. In the case of standard GMAW, the average current was $299 \mathrm{~A}$, while it was increased to $321 \mathrm{~A}$ with a $140 \%$ cold wire addition. Using Equation 5, one can calculate that for this situation, the electromagnetic force increased approximately $15 \%$ in CW-GMAW regarding the conventional GMAW. This value, however, represents a rough approximation as the droplet diameter decreases with cold wire introduction, causing $f\left(D_{p}, r, \theta\right)$ to vary. In fact, one can expect that the variation in electromagnetic force be higher than $15 \%$ in spray regime.

This increase in magnetic force represents an increase in 

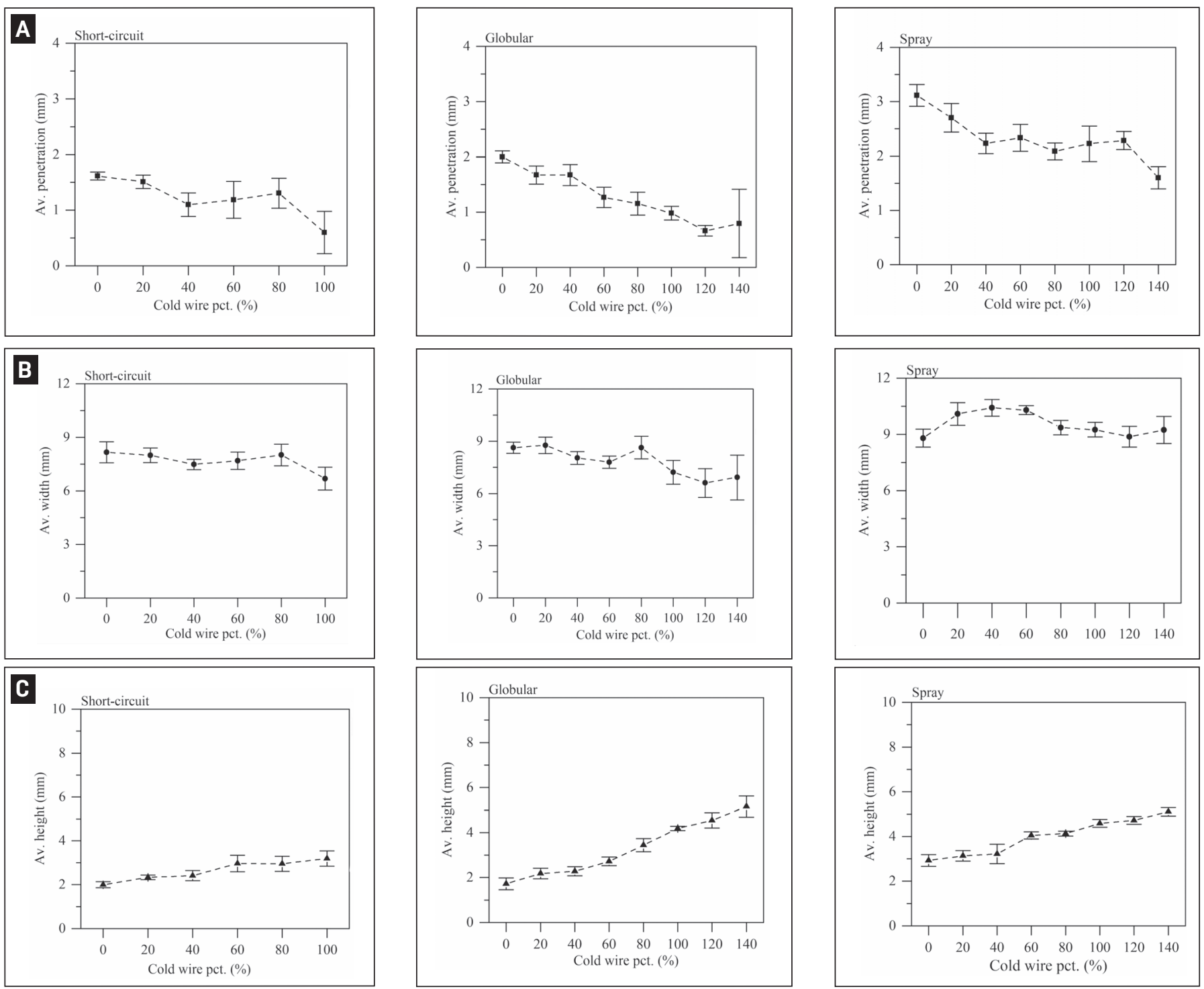

Fig. 17 - Geometric features of the beads. A - Penetration depth; B - width; $C$ - height.

the droplet detachment frequency and, consequently, a decrease in droplet diameter, for instance in spray since this force dominates the metal transfer in this transfer mode. Ultimately, this variation in electromagnetic force will represent changes in bead geometry, as this force is related to droplet momentum, which plays a role in defining the bead geometry.

\section{Weld Bead Geometrical Features}

The rationale for the differences observed during CWGMAW are related to arc pinning to the cold wire as that feed rate increases. This results in the droplet momentum and arc pressure to be directed toward the semi-solid cold wire that shields the weld pool, limiting the penetration. This is called the cold wire shielding effect of the weld pool.

Overall, this limiting of penetration also impacts the finger-like penetration that is suppressed by the cold wire through the shielding effect mentioned earlier. In the spray condition in particular, complete suppression of the finger- like profile occurs when the arc is completely pinned to the cold wire, at a $140 \%$ cold wire feed rate. Regarding the increase in bead height, the rate of height increase is higher than in spray. A possible rationale for that is the thermal balance of the arc is more efficient in globular than in spray where the losses of energy and mass are higher. On the other hand, no clear trend is detected in terms of bead width.

\section{Correlation between Dilution and Melting Efficiency}

Dilution and melting efficiency are interrelated as already pointed out. Overall, higher values of dilution represent higher values of melting efficiency. As dilution varies directly with arc power, then arc power can be related to melting efficiency. Simply put, high values of arc power imply higher dilution values. However, one cannot say that higher values of power will cause higher values of melting efficiency. As the welding system is subjected to energy losses, increasing the energy level could represent increasing the energy wasting factors that will limit the growing of melting efficiency. 

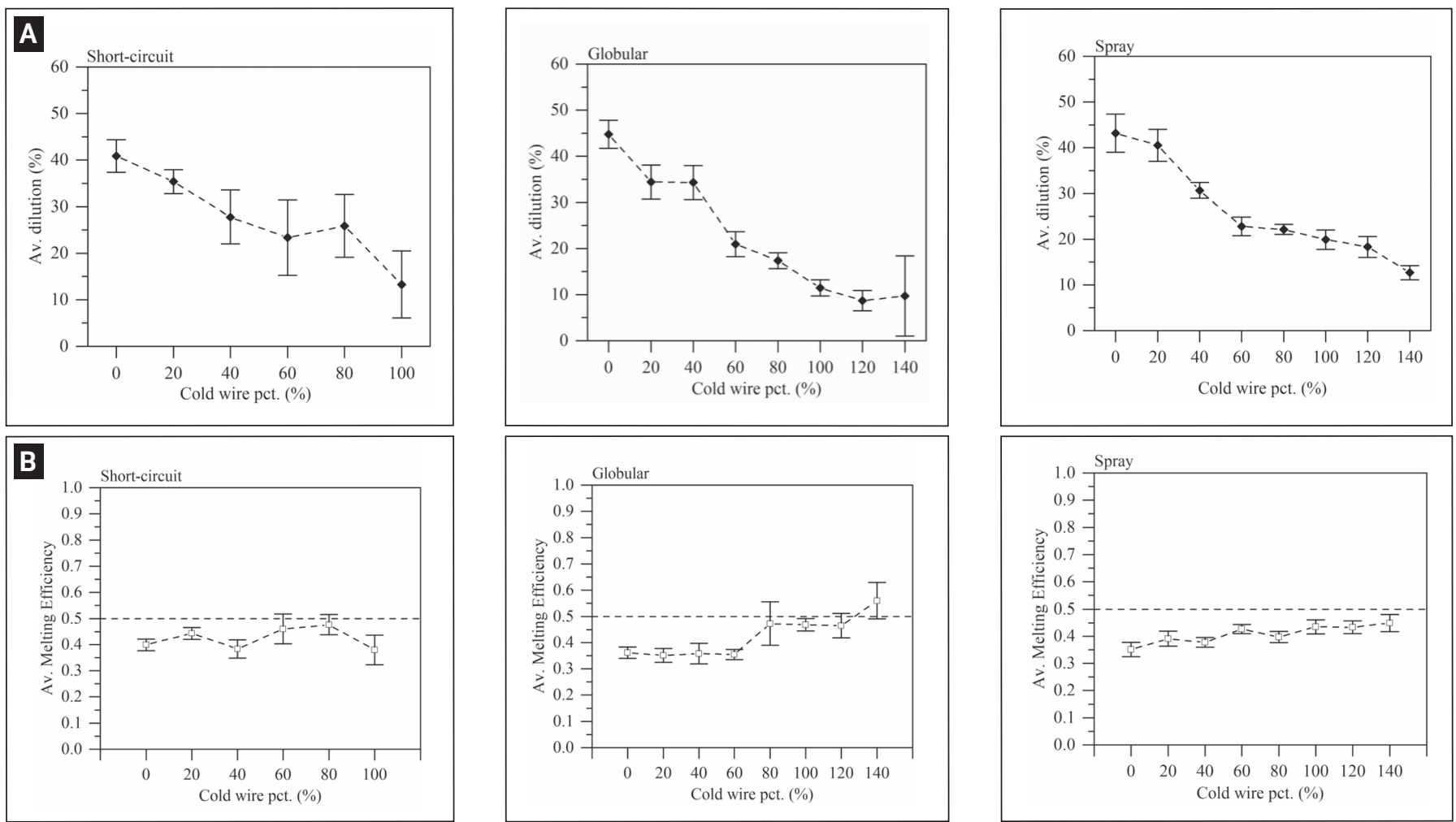

Fig. $18-A-$ Dilution; B - melting efficiency for the three natural transfer modes.

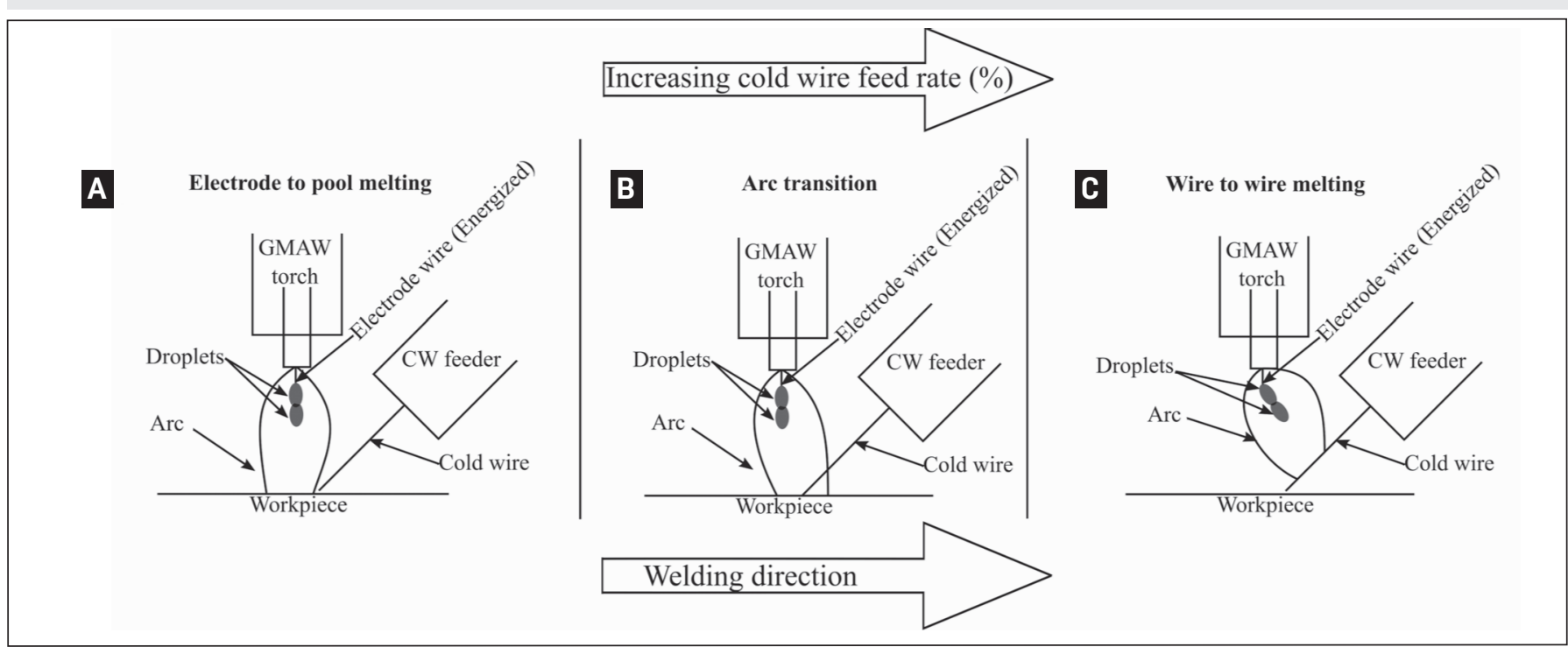

Fig. 19 - Arc positions in relation to the cold wire as observed for different cold wire feeding. A - Electrode to pool melting; B arc transition; $\mathrm{C}-$ wire to wire melting.

The results presented in the section titled "Dilution and Melting Efficiency" show that dilution and melting efficiency are decoupled in CW-GMAW. The decrease in dilution is dependent on the reduction of penetration caused by the cold wire shielding of the weld pool. As the deposition increases due to cold wire addition, the factors responsible for melting efficiency of the filler metal increased (Equation 3), causing the total melting efficiency to increase. Clearly, the rate of increase in melting efficiency depends on arc power, which differs for each metal transfer regime.
For the three transfer modes studied in this work, namely, short circuit, globular, and spray, one can see that globular transfer mode, in some conditions, can induce measured values of melting efficiency, which are apparently exceeding the theoretical limit of 0.5 . This might be explained by a rather simple energy balance in which losses by radiation and convection can be absorbed by the cold wire and reintroduced into the arc pool system, consequently increasing the melting efficiency.

As for the short-circuit case, the system itself has lower 
energy compared to other transfer modes, and it loses thermal energy transformed in spatter momentum during short circuits. This leaves less energy available to be absorbed by the cold wire. The inverse occurs in the case of spray transfer, where higher energy is available to be lost by radiation and plasma convection since the arc length is longer, impeding melting efficiency to approach the theoretical limit, even for spray parameters at the highest cold wire feed rates.

\section{Conclusions}

Bead-on-plate welds were performed to investigate the metal transfer dynamics and its influence on dilution and melting efficiency for the three natural transfer modes: short circuit, globular, and spray. Based on the findings, the following conclusions can be drawn:

1) Cold wire addition leads to changes in arc position in the longitudinal axis, which were referred to here as arc melting, transition, and weld pool arc pinning. This last position occurs for high cold wire feed rates, where the arc is completely pinned to the cold wire.

2) The introduction of cold wire caused significant changes in droplet diameter and detachment frequency for short circuit and spray modes while no trend was detected for globular. This change is due to the current increase determined by increasing the cold wire feed rates. However, this increase in current does not entail an increase in penetration depth.

3) The variation in arc position entails different cold wire energy absorption capacities. For instance, when the cold wire melts in a melt pool, its absorption heat capacity is maximum, which determines low dilution while higher melting efficiencies are obtained.

\section{Acknowledgments}

The authors would like to acknowledge the Natural Sciences and Engineering Research Council of Canada (NSERC) and the TransCanada Pipelines Inc. for the funding of this work.

\section{References}

1. Miller, C., Crawford, M. H., and French, R. 2002. WeldingRelated Expenditures and Productivity Measurement in U.S. Manufacturing, Construction, and Mining Industries. Miami, Fla.: American Welding Society.

2. Suban, M. and Tušek, J. 2001. Dependence of melting rate in MIG/MAG welding on the type of shielding gas used. J. Mater. Process. Technol. 119: 185-192. DOI: 10.1016/S0924160136(01)00940-2

3. Li, K. H., and Zhang, Y. M. 2008. Consumable double-electrode GMAW-Part 1: The process. Welding Journal 87(1): 11-s to 17-s.

4. Mohammadijoo, M., Kenny, S., Collins, L., Henein, H., and Ivey, D. G. 2017. Characterization of HAZ of API X70 microalloyed steel welded by cold-wire tandem submerged arc welding. Metall. Mater. Trans. A. 48(5): 2247-2259. DOI: 10.1007/s11661-017-4041-x

5. Mohammadijoo, M., Kenny, S., Collins, L., Henein, H., and Ivey, D. G. 2016. Effect of cold-wire addition in the TSAW process on microstructure and mechanical properties of the HAZ of X70 microalloyed pipeline steel. Oper. Monit. Maintenance; Mater. Join. Vol. 3. Calgary, Alberta, Canada: ASME, p. V003T05A051. DOI: 10.1115/IPC2016-64549

6. Chen, S. J., Zhang, L., Wang, X. P., and Wang, J. 2015. Stability of the cross-arc process - A preliminary study. Welding Journal 94(4): 158-s to 168-s.

7. DuPont, J. N., and Marder, A. R. 1995. Thermal efficiency of arc welding processes. Welding Journal 74(12): 406-s to 416-s.

8. Hackenhaar, W., Gonzalez, A. R., Machado, I. G., and Mazzaferro, J. A. E. 2017. Welding parameters effect in GMAW fusion efficiency evaluation. Int. J. Adv. Manuf. Technol. 94: 497-507. DOI: 10.1007/s00170-017-0888-7

9. da Silva, F. G. 2010. Estudo da viabilidade do processo de soldagem FCAW com adição de arame frio aplicado a indústria naval (Feasibility study on cold wire FCAW process applied to naval construction). Federal University of Pará. http://www.lcam.ufpa.br/ attachments/article/15/DISS_FABIO_SILVA.pdf.

10. Ribeiro, R. A., Dos Santos, E. B. F., Assunção, P. D. C., Maciel, R. R., and Braga, E. M. 2015. Predicting weld bead geometry in the novel CW-GMAW process. Welding Journal 94(9): 301-s to 311-s.

11. Assunção, P. D. C., Ribeiro, R. A., Dos Santos, E. B. F., Gerlich, A. P., and Braga, E. M. 2017. Feasibility of narrow gap welding using the cold-wire gas metal arc welding (CW-GMAW) process. Weld. World. 61: 659-666. DOI: 10.1007/s40194-017-0466-5

12. Costa, E. S., Assunção, P. D.C., Dos Santos, E. B. F., Feio, L. G., Bittencourt, M. S. Q., and Braga, E. M. 2017. Residual stresses in cold-wire gas metal arc welding. Sci. Technol. Weld. Join. 22: 706713. DOI: 10.1080/13621718.-2017.1306014.

13. Marques, L. F. N., Dos Santos, E. B. F., Gerlich, A. P., and Braga, E. M. 2017. Fatigue life assessment of weld joints manufactured by GMAW and CW-GMAW processes. Sci. Technol. Weld. Join. 22: 87-96. DOI: 10.1080/13621718.-2016.1194735

14. AWS A5.18/A5.18M, Specification for Carbon Steel Electrodes and Rods for $G$ as Shielded Arc Welding. 2005. Miami, Fla.: American Welding Society.

15. Soderstrom, E. J., and Mendez, P. F. 2008. Metal transfer during GMAW with thin electrodes and $\mathrm{Ar}-\mathrm{CO}_{2}$. Welding Journal 87(5): 124-s to 133-s.

16. Montgomery, D. C. 2012. Design and Analysis of Experiments, $8^{\text {th }}$ ed., New York, N.Y.: John Willey \& Sons. DOI: 10.1198/ tech.2006.s372

17. Fuerschbach, P. W., and Knorovsky, G. A. 1991. A study of melting efficiency in plasma arc and gas tungsten arc welding. Welding Journal 70(11): 287-s to 297-s.

18. Murray, P. E., and Scotti, A. 1999. Depth of penetration in gas metal arc welding. Sci. Technol. Weld. Join. 4: 112-117. DOI: 10.1179/136217199101537644

19. DuPont, J. N., and Marder, A. R. 1996. Dilution in single pass arc welds. Metall. Mater. Trans. B 27: 481-489. DOI: 10.1007/BF02914913

20. Zhang, G., Shi, Y., Zhu, M., and Fan, D. 2017. Arc characteristics and metal transfer behavior in narrow gap gas metal arc welding process. J. Mater. Process. Technol. 245: 15-23. DOI: 10.1016/j.jmatprotec.2017.02.006

21. Amson, J. C. 1965. Lorentz force in the molten tip of an arc electrode. Br. J. Appl. Phys. 16: 1169-1179. DOI: 10.1088/05083443/16/8/316

RAFAEL DE ARAÚJO RIBEIRO (rdearauj@uwaterloo.ca) and A. P. GERLICH are with the Centre for Advanced Materials Joining (CAMJ), University of Waterloo, Waterloo, Ontario. E. B. F. DOS SANTOS is with Liburdi Automation Inc., Dundas, Ontario; and $P$. D. C. ASSUNÇÃO and E. M. BRAGA are with Metallic Materials Characterization Laboratory, Federal University of Pará, Guamá, Belém - PA, Brazil. 